University of Nebraska - Lincoln

DigitalCommons@University of Nebraska - Lincoln

Summer 7-26-2012

\title{
Hepatic Mitochondrial Efficiency in Lines of Mice Differing in Feed Intake
}

Thomas Murphy

University of Nebraska-Lincoln, twmurph88@gmail.com

Follow this and additional works at: https://digitalcommons.unl.edu/animalscidiss

Part of the Other Animal Sciences Commons

Murphy, Thomas, "Hepatic Mitochondrial Efficiency in Lines of Mice Differing in Feed Intake" (2012).

Theses and Dissertations in Animal Science. 55.

https://digitalcommons.unl.edu/animalscidiss/55

This Article is brought to you for free and open access by the Animal Science Department at DigitalCommons@University of Nebraska - Lincoln. It has been accepted for inclusion in Theses and Dissertations in Animal Science by an authorized administrator of DigitalCommons@University of Nebraska - Lincoln. 
Hepatic Mitochondrial Efficiency in Lines of Mice Differing in Feed Intake

by

Thomas W. Murphy

\author{
A THESIS \\ Presented to the Faculty of \\ The Graduate College at the University of Nebraska \\ In Partial Fulfillment of Requirements \\ For the Degree of Master of Science
}

Major: Animal Science

Under the Supervision of Professor Merlyn K. Nielsen

Lincoln, Nebraska

August 2012 
HEPATIC MITOCHONDRIAL EFFICIENCY IN LINES OF MICE DIFFERING IN

FEED INTAKE

Thomas W. Murphy, M.S.

University of Nebraska, 2012

Adviser: Merlyn K. Nielsen

Selection was practiced for high (MH) and low (ML) heat loss using direct calorimetry to create lines of mice differing in feed intake per unit BW (FI/BW). Selection occurred for both criteria in each of 3 replications (R); an unselected control (MC) was also maintained in each replicate. A total of 25 generations of selection was practiced; the 9 lines are presently maintained without selection. As a percentage of $\mathrm{MC}$, mice of $\mathrm{MH}$ and ML lines differed in heat loss and FI/BW by 56 and 34\%, respectively, when selection ceased. The 218 male mice measured in the present study came from R1-R3 and multiple generations. The purpose of this study was to determine hepatic mitochondrial efficiency in mice at maintenance across the genetic lines. Additionally, line comparisons of BW, FI/BW, liver weight per BW (LW/BW), and body composition were analyzed. Following measurement of FI and BW over a 2-wk period, mice were euthanized, and their livers were extracted and weighed. Livers were homogenized and mitochondria were isolated in buffer for measurement of oxygen consumption, and hence mitochondrial activity, using a Clark-type oxygen electrode. Mitochondria of ML mice expressed greater $(\mathrm{P}<0.03)$ respiratory control ratio by $22 \%$ than that for $\mathrm{MH}$ mice, revealing greater degree of uncoupling, thus less efficient electron transport in $\mathrm{MH}$ mice. There were no line differences $(\mathrm{P}>0.99)$ in ADP:Oxygen ratio. There was no difference in BW between 
$\mathrm{MH}$ and ML mice $(\mathrm{P}>0.35)$, however MC mice were heavier $(\mathrm{P}<0.02)$. Difference in FI/BW ( $\mathrm{P}<0.001)$ was large with $\mathrm{MH}$ mice consuming 34\% more than ML mice. No line differences in $\mathrm{LW} / \mathrm{BW}$ were found. Selection tended to affect on fat percentage $(\mathrm{P}<$ 0.07) with ML mice being 19\% fatter than MH mice. RCR differed between mice of $\mathrm{MH}$ and ML lines as expected, however regression analysis revealed that it explained essentially no variation in feed intake per BW. 


\section{Acknowledgements}

I cannot begin acknowledging the rest of the people who have gotten me to the place I am today without first mentioning my wonderful mother and family. The support that you have given to me was, and always will be, a constant, guiding beacon. You have always encouraged me to follow my dreams and to use my talents and penchant for discovering how things work to the best of my abilities. Your encouragement has shown me that success is not measured in dollars and cents, but in happiness. When the day comes that I find myself truly successful, I hope I can give half as much to you as you have given me. Thank you, for everything.

Joining the Animal Science department at the University of Nebraska was the best career decision I have made. My professors throughout my undergraduate and graduate studies, especially those on my advisory committee, truly care about the education of their students. The research of Dr. Miller, Dr. Ciobanu, and Dr. Spangler represents the future of our industry, thank you for all of your help and insight. I'd also like to thank Rhonda and all the lab managers that do the "behind the scenes" work, without you this project would have never been completed. Lastly, a special thank you to Dr. Nielsen. It seems not too long ago I was sitting in the back row of your undergraduate Breeding course. I didn't have the best grade in the class and maybe on that criterion I wasn't the best choice as a graduate student. Perhaps in attribute to your extensive work with indexes you are able to see students in the big picture. This comes with years of experience, wisdom, and patience rivaled by few. Thank you for instilling the tandem of knowledge and confidence in me. It is something I will always carry. 


\section{Table of Contents}

Introduction 1

Literature Review 4

I. Variation in Maintenance Energy Requirements $\ldots \ldots \ldots \ldots \ldots \ldots \ldots \ldots \ldots \ldots \ldots$

A. Selection on Growth Rate and its Correlated Responses..............6

B. Selection on Feed Conversion and Residual Feed Intake and its Correlated Responses.......................................

C. Selection on Heat Loss and its Correlated Responses..................10

D. Other Research with the Nebraska Heat Loss Selection Lines.........13

II. Mitochondrial Systems........................................... 15

A. Measuring Mitochondrial Efficiency............................ 18

B. Biological Reasoning for Mitochondrial Uncoupling and UCP activity in the Nebraska Heat Loss Selection Lines........................20

C. Variation of Mitochondrial Respiration within Species.............21

D. The Role of Mitochondrial Components in Maintenance Requirements................................................23

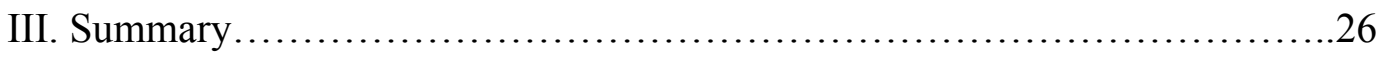

Materials and Methods.....................................................27

I. Mice.......................................................... 28

II. Feed Intake Trial.................................................. 30

III. Liver Extraction................................................. 31

IV. Isolation of Mitochondria.......................................... 32

V. Determination of Percent Fat........................................ 34 
VI. Spectrometry of Mitochondrial Sample.

VII. Clark-type Oxygen Electrode......................................... 35

VIII. Mitochondrial Respiration Collection..................................... 37

IX. Analysis of Respiration Results.......................................38

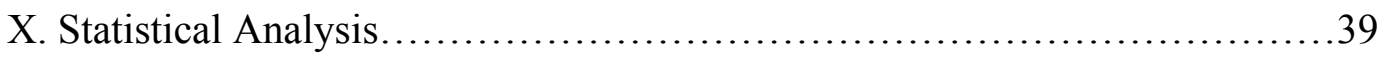

Results and Discussion...................................................... 42

I. Body Weight and Feed Intake.....................................43

II. Body Composition and Liver Weight..................................45

III. Mitochondrial Traits.................................................49

IV. Assigning the fraction of line differences in Feed per BW that is explained by differences in RCR................................................56

V. Partial Correlation Coefficients........................................58

VI. Suggestions for Further Research Further Investigating Mitochondrial

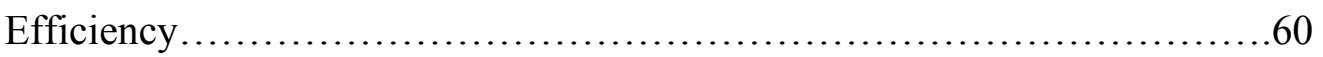

Summary and Conclusions..............................................63

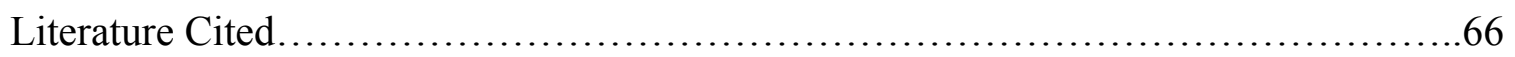

\section{List of Tables}

Materials and Methods

1. Number of animals used in data analysis by Generation, Replicate, and Line..29 
Results and Discussion

2. Average body weights \pm SE during the feed intake trial and feed intake (2-wk total) per $\mathrm{BW}$ for the $\mathrm{ML}, \mathrm{MC}$, and $\mathrm{MH}$ lines across all replicates and generations

3. Means $\pm \mathrm{SE}$ for percent fat and liver weight per body weight for the ML, MC, and $\mathrm{MH}$ lines across all replicates and generations

4. Means \pm SE for mitochondrial protein, State 2, State 3, and State 4 for the ML, $\mathrm{MC}$, and $\mathrm{MH}$ lines across all replicates and generations

5. Means $\pm \mathrm{SE}$ for $\mathrm{RCR}$ and $\mathrm{ADP}: \mathrm{O}$ for the $\mathrm{ML}, \mathrm{MC}$, and $\mathrm{MH}$ lines across all replicates and generations

6. Partial correlation coefficients of traits measured within generation-linereplicate and the interaction of line and replicate

\section{List of Figures}

\section{Literature Review}

1. Line $(\mathrm{MH}=$ high, $\mathrm{ML}=$ low, $\mathrm{MC}=$ control, set to zero) means for heat loss $\left(\mathrm{kcal} / \mathrm{kg}^{0.75} / \mathrm{d}\right)$ averaged across all three replicates of selection. Selection ceased between Generations 16 and 42 then was renewed............................. 12

2. The inner membrane of the mitochondria and the electron transport chain complexes 
Materials and Methods

3. Homogenizing minced liver......................................... 32

4. The mitochondrial pellet........................................ 34

5. An example of a Clark-type oxygen electrode............................ 36

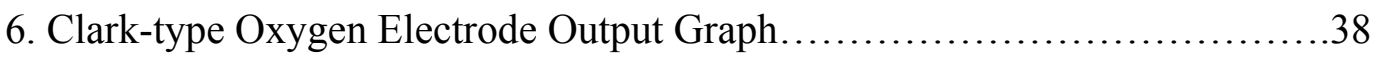

Results and Discussion

7. Average $\mathrm{BW}$ of $\mathrm{ML}, \mathrm{MC}$, and $\mathrm{MH}$ lines of mice across all generations and replicates........................................................44

8. Average feed intake per BW of ML, MC, and MH lines of mice across all generations and replicates.............................................46

9. Means for percent fat of ML, MC, and MH lines of mice across all generations and replicates..................................................... 48

10. Means for liver weight per BW of ML, MC, and MH lines of mice across all generations and replicates..........................................48

11. Mean rates of respiration for states 2, 3, and 4 for the ML, MC, and MH lines

of mice........................................................... 50

12. Means for ADP:O and RCR for the ML, MC, and MH lines of mice........54 
Introduction 
The cost associated with feeding animals is the largest economic input in any animal agriculture operation, representing more than $50 \%$ of the total expenses in most production settings. From a system-wide perspective, feeding animals to meet their maintenance requirements is the greatest of these costs. Ferrell and Jenkins (1985) determined that maintenance requirements are responsible for $70-75 \%$ of the total feed energy requirements in an average herd of beef cattle. Additionally, there exists considerable genetic variation for maintenance energy requirements and with this, opportunity to select for efficient energy utilization.

Changing maintenance requirements in a population of animals can result from selection on various measurable phenotypes, one being heat loss. Nielsen and others (1997a) at the University of Nebraska-Lincoln used direct calorimetry to select for and against heat loss in mice thus creating a high heat loss line $(\mathrm{MH})$, a low heat loss line (ML), and an additional control line (MC) with no selection applied. Selection was carried out for 15 generations with three independent replicates, and it was determined that divergence in heat loss was successful with an overall heritability of 0.28 . This selection experiment was extended with identical methods by McDonald and Nielsen (2007) for an additional 9 generations with similar results. After the second selection experiment the ML and $\mathrm{MH}$ lines differed by $56 \%$ when compared to the MC line for heat loss, and $34 \%$ for feed intake per body weight. In this population of animals, the $\mathrm{MH}$ mice consumed the most feed with no difference in body weight.

Presently the Nebraska heat loss lines are maintained without selection and experimental objectives have been focused on determining various indicator traits that 
create differences in maintenance energy requirements between the lines. For example, the $\mathrm{MH}$ line is leaner and has a greater rate of locomotor activity (Mousel, 2001).

Rolfe and Brown (1997) determined that $90 \%$ of mammalian oxygen consumption is mitochondrially related. Additionally, Lehinger (2005) states that $90 \%$ of ATP, the basic energy substrate used by the cell, is created by the mitochondria. So with this the mitochondria seem to be a starting point to determine differences in maintenance energy requirements between the heat loss selection lines, and was the basis of McDonald's (2008) experiment comparing mouse lines differing in feed intake. Mitochondrial efficiency is measured with a Clark-type oxygen electrode by comparing rates of oxygen consumption. Although no statistical differences were found between the Nebraska heat loss lines in hepatic mitochondrial traits by McDonald et al. (2009), numerical differences were enough to justify an additional experiment with renewed mitochondrial sample preparation and more precise oxygen consumption measurements. Therefore, the objective of the present study was to more precisely determine whether or not selection for and against heat loss has changed basic hepatic mitochondrial function in mature male mice. The relationship of mitochondrial traits, if any, with feed energy maintenance requirement, liver weight, and body composition was also analyzed. 


\section{Literature Review}




\section{Variation in Maintenance Energy Requirements}

Feed for livestock supplies the necessary energy requirements for production (growth, milk, wool, reproduction) and maintenance for all the animals in an operation. The National Research Council (NRC, 1996) defines net energy for maintenance (NEm) as the heat production of an animal when feed intake is zero. Ferrell and Jenkins (1985) determined that maintenance requirements are responsible for $70-75 \%$ of the total energy requirements in a herd of cattle. Differences in maintenance energy requirements among animals can be accounted for by environmental and physiological components such as: age, sex, breed, state, body composition, locomotor activity, and organ mass. Because feeding animals to meet their maintenance requirements is of such economical significance to an operation, investigating the degree at which the above factors influence variation in maintenance is of great importance.

Ferrell and Jenkins (1985) conducted an experiment to compare the maintenance energy requirements between cows within a breed and among different breeds. Here, several breeds and their crosses were analyzed to determine and the relationships between maintenance efficiency, production, and visceral organ mass. They determined that there were significant differences and variation in maintenance energy requirements between breeds and between animals within one breed exists. They noted that the maintenance requirements of a cow seem to be positively associated with her level of production. They also concluded that metabolism in the visceral organs is a major contributor to an animal's energy expenditures. Ferrell and Jenkins (1985) determined that there is large variation in energy expenditures among animals in a cowherd. With some animals 
requiring more energy for production than others, this would suggest large differences in maintenance efficiency and thus a starting point for selection.

Selection to reduce maintenance requirements in animals has been approached using several different phenotypes. Some researchers have selected replacement animals on rate of gain (Canolty and Koong, 1976; Rios et al., 1986; Dunnington and Siegel, 1996), feed conversion or residual feed intake (Bishop et al., 1991 a, b; Richardson et al., 1998; Smith et al., 2011), and heat loss (Nielsen et al., 1997 a, b; McDonald and Nielsen, 2007).

\section{Selection on Growth Rate and its Correlated Responses}

Canolty and Koong (1976) utilized a line of mice with forty-one generations of selection for increased post weaning growth rate and compared them to an unselected control line. The objectives of the experiment were to determine the line differences in maintenance requirements and growth efficiency. The results showed that maintenance requirements did not differ between the selected and unselected lines, both requiring 176 kcal per unit body size to meet maintenance. They also determined that the rapid growth line was more efficient in increasing body energy, but that the lines deposited energy into lean tissue at the same rate. The differences in energy deposition efficiency came in fatty tissues, where the rapid growth line deposited energy into fat at a greater rate than the control line.

Similar to Canolty and Koong (1976), Rios et al. (1986) utilized lines of rats selected for post-weaning gains over thirty-four generations. However, their experiment presented the opportunity to study both ends of the spectrum in post-weaning gain with 
divergent selection. The up (U) and down (D) post-weaning selection lines were compared with the control (C) line for ADG, ADI, G/F, average heat loss (AHL), and body composition. They concluded that the $\mathrm{U}$ rats had $11 \%$ greater ADG and $6 \%$ greater ADI when compared to $\mathrm{C}$. This led to the $\mathrm{U}$ line being more efficient in post-weaning gain with a $6 \%$ higher $\mathrm{G} / \mathrm{F}$. Opposite to that, rats from the $\mathrm{D}$ line had $8 \%$ lower $\mathrm{ADG}, 3 \%$ less $\mathrm{ADI}$, and were $5 \%$ less efficient in $\mathrm{G} / \mathrm{F}$ than $\mathrm{C}$. They also determined the lines were similar for AHL with the $\mathrm{U}$ and $\mathrm{D}$ lines losing $1 \%$ and $-1 \%$ heat, respectively, to C. They noted that although there were small differences in body fat in their study, past research with the same lines found $\mathrm{D}$ rats to be a little fatter. These results are consistent with Canolty and Koong (1976) with respect to efficiency of gain, but not with fat deposition.

Dunnington and Siegel (1996) studied poultry lines where long-term (38 generations) divergent selection for gain had been applied. Their objectives were to determine the relationship of selection for $\mathrm{BW}$ gain with traits such as feed intake, ADG, feed efficiency and body composition, among others. After selection for high (HWS) and low (LWS) body weight gain, realized heritability for 8-wk BW was 0.22-0.28 and 0.230.28 for HWS and LWS, respectively. Their findings were consistent with Canolty and Koong (1976) and Rios et al. (1986). HWS chickens consumed more feed, had a higher ADG, and were more efficient than LWS chickens were. Additionally, HWS seemed to be fatter, agreeing with Canolty and Koong (1976).

Selection on Feed Conversion and Residual Feed Intake and its Correlated Responses

Rather than selecting directly for gains in body weight over a given period of time, some researchers have practiced selection on aforementioned associated traits, 
namely feed conversion and feed efficiency. Feed efficiency can be measured directly as a gain to feed ratio or, more recently, the indicator residual feed intake has been used.

Bishop et al. (1991a) reported results from their selection experiment on feed conversion in Angus cattle. From the years 1979 to 1983 they divergently selected replacement bulls after a feed intake trial to determine feed:gain. They found that progeny from bulls from high feed conversion, less feed to gain, line (more desirable) consumed the same amount of feed but had a greater ADG, and thus were more efficient. They also found the high feed conversion line to have greater amounts of subcutaneous fat. They commented that this might be due to a lower maintenance requirement for fat than for lean tissue, agreeing with Canolty and Koong's (1976) selection experiment for post-weaning gain in mice.

Continuing this experiment, Bishop et al. (1991b) reported the genetic and phenotypic correlations as well as the estimated heritability of feed conversion in these lines of Angus cattle. The heritability of unadjusted feed conversion, just looking at feed:gain, was estimated to be 0.26 . As recommended by the Beef Improvement Federation (BIF, 1986), they also adjusted feed conversion rate for differences in maintenance requirements $\left(\mathrm{BW}^{0.75}\right)$. After this adjustment they found a heritability of 0.46. A correlation between the unadjusted and adjusted feed conversion rates was 0.97 . The differences between the two heritability estimates reflect differences in BW and maintenance requirements. Their implications suggest that when selecting for improved feed conversion, negative selection should also be applied to subcutaneous fat.

Measuring and selecting for feed conversion rate defines the ability of an animal to efficiently convert feed intake to gains in BW. Some researchers propose an alternative 
to the ratios feed conversion rate or feed efficiency to capture feed intake unexplained by expected production and maintenance requirements. This measurement, known as residual feed intake (RFI), is the difference between an animal's actual feed intake and its expected feed requirements for maintenance and growth. RFI is measured in units of feed.

Using several studies, Luiting and Urff (1991) concluded that upwards of 80\% of feed consumption among hens remains unaccounted for by body weight, daily egg mass production, and weight gain. Thus, hens with similar mature body weights and production levels may exhibit large differences in feed consumption and feed efficiency. They referred to this unexplained variation as residual feed consumption (RFC), called residual feed intake (RFI) by others. They hypothesized that this variation may be the cause of hen differences in maintenance requirements, partial energy utilization efficiency, and unaccounted energy demanding processes. To quantify this variation in RFC, White Leghorn hens were placed on a feed intake trial during a 44-wk laying period. Data analysis revealed a RFC standard deviation of 4 to $8 \mathrm{~g} / \mathrm{d}$ with a repeatability of 0.52 to 0.58 . They showed that RFC shows a large amount of systematic and permanent variation. Luiting and Urff (1991) concluded that variation in RFC was mainly due to hen differences in maintenance requirements per unit metabolic body weight $\left(\mathrm{BW}^{0.75}\right)$

Jensen et al. (1992) placed 650 bull calves into two production periods to estimate residual energy intake (REI) with ad libitum feeding. They estimated a REI heritability of 0.30. They found REI was both phenotypically and genetically correlated to daily intake. With this, selection for a decrease in REI would serve to decrease daily intake. 
Additionally, Jensen et al. (1992) note that selection for a decrease in REI would yield fatter animals, as genetically efficient animals tend to be fatter.

Richardson et al. (1998) utilized a group of animals whose parents had been ranked for net feed efficiency (NFE), the same as RFI by others. They showed that a single generation of selection for and against NFE did not produce steers with differences to meet market requirements. Selection for high NFE (more desirable, same as negative RFI) parents yielded steers that grew at similar rates while consuming less feed than steers from low NFE (positive RFI) parents. The high NFE progeny had less fat and a smaller REA than low NFE progeny.

Smith et al. (2011) looked at the correlated responses of selection on decreased RFI in swine. Their objectives were to determine the effects selection on low RFI had on pork composition and quality. Pigs from the fifth generation of selection for decreased RFI (select) were compared to an unselected control line (control). They found that carcasses from the select line tended to have less backfat, had a greater loin depth, and greater fat free lean. These results are in agreement with Richardson et al. (1998) but different than those hypothesized by Jensen et al. (1992) and other researchers selecting for increased gain or feed conversion that saw increases in efficiency but generally yielded fatter animals.

\section{Selection on Heat Loss and its Correlated Responses}

Selection for growth rate, feed conversion, and RFI has shown to affect the maintenance requirements in a group of animals. Maintenance requirements have 
previously been defined by the National Research Council (NRC, 1996) as the heat production of an animal when feed intake is zero. Studies have been designed to determine the relationship of heat production and maintenance energy requirements in animals. Shuey et al. (1993) found that fasting heat production (FHP) is correlated $\left(\mathrm{r}^{2}=\right.$ $0.73)$ with maintenance energy requirements $\left(\mathrm{ME}_{\mathrm{m}}\right)$ in heifers. Additionally, Hotovy et al. (1991) estimated heritabilities of $0.52 \pm 0.22$ and $0.75 \pm 0.13$ for FHP and $\mathrm{ME}_{\mathrm{m}}$, respectively. With this in mind, some researchers have practiced selection against heat loss in animals to decrease their maintenance requirements.

Nielsen et al. (1997a) reported results from their heat loss selection experiment in mice. Using direct calorimetry to measure heat loss per unit metabolic size $\left(\mathrm{kcal} / \mathrm{kg}^{0.75} / \mathrm{d}\right)$, they selected with measurement only in males for 15 generations. Mice were selected for high heat loss (MH), low heat loss (ML) and a control line (MC) was maintained without selection. The three lines were produced in three replicates, totaling nine unique lines. Their results showed that selection for and against heat loss was effective at creating differences in maintenance requirements in mice. They found heat loss to be moderately heritable, $0.31 \pm 0.01$ and $0.28 \pm 0.01$, for the $\mathrm{MH}$ and ML lines respectively. After 26 generations without selection, McDonald and Nielsen (2007) renewed heat loss selection in these lines for an additional 9 generations. Renewed selection showed lower heritability for heat loss, $0.16 \pm 0.05$ and $0.07 \pm 0.006$ for the $\mathrm{MH}$ and ML lines respectively. Across generations there was variation in direction and magnitude of response to selection, and this is shown graphically in Figure 1. 


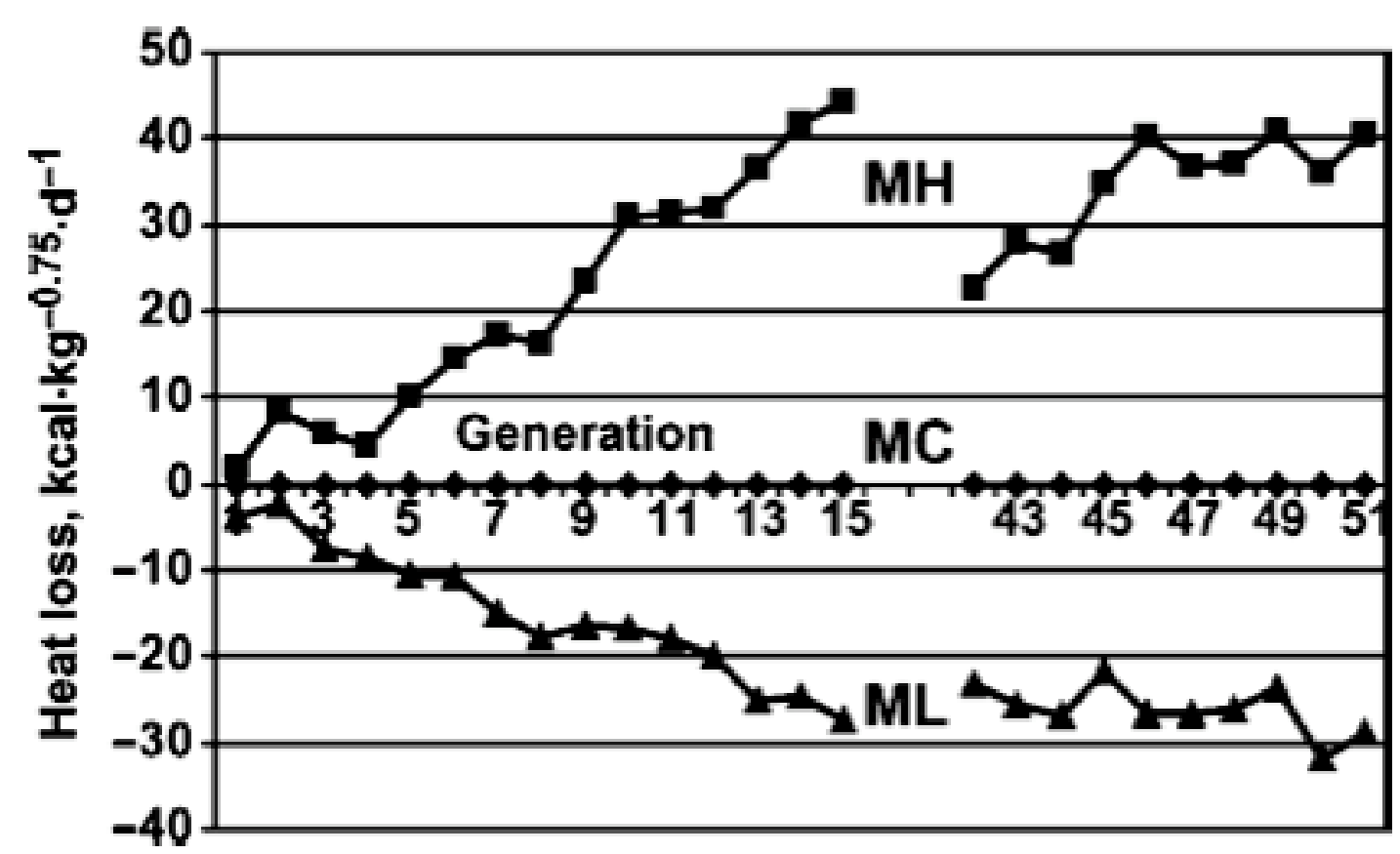

Figure 1. Line $(\mathrm{MH}=$ high heat loss, $\mathrm{ML}=$ low heat loss, $\mathrm{MC}=$ control, set to zero) means for heat loss $\left(\mathrm{kcal} / \mathrm{kg}^{0.75} / \mathrm{d}\right)$ averaged across all three replicates of selection. Selection ceased between Generations 16 and 42 and then was renewed.

Nielsen et al. (1997b) and McDonald and Nielsen (2007) measured the responses in feed intake, body mass, and body composition traits after selection. Nielsen et al. (1997b) found a genetic correlation of feed intake with heat loss ranging from 0.27 0.40. Feed intake per unit body weight was found to change with selection as the $\mathrm{MH}$ mice consumed more feed than the MC mice. Opposite to this, the ML mice consumed less feed than the MC mice. After the first series of selection, MH and ML mice differed by $20.6 \%$ of the MC mean in feed intake. After renewed selection, the selected lines differed by $34.0 \%$ of the MC mean in feed intake per unit of BW.

Nielsen et al. (1997b) also reported the line differences in body composition. After the initial 15 generations of selection the MH mice showed significantly less body 
fat than the ML mice with MC mice being intermediate to them. There were no line differences in BW. These results agree with Bishop et al. (1991 a,b) and others who found that more efficient animals are generally fatter. After renewed selection by McDonald and Nielsen (2007), the MH mice were still leaner than the ML mice after being corrected for BW. This correction was used because mice of the unselected MC line were statistically heavier than the selected lines, on average $2.86 \pm 0.12 \mathrm{~g}$ and $3.10 \pm$ $0.12 \mathrm{~g}$ more than $\mathrm{MH}$ and ML mice, respectively.

\section{Other Research with the Nebraska Heat Loss Selection Lines}

Moody et al. (1997) continued research with the heat loss selection lines created by Nielsen et al. (1997 a,b). Objectives of the study were to determine the variability in feed intake, fatness, and organ weight of the MH, ML, and MC lines. The results of Moody et al. (1997) confirmed Nielsen et al. (1997 a,b). They found the MH mice to consume $15-21 \%$ more feed than the ML mice. The divergence in feed intake was only half of the divergence in heat loss between the selection lines. This was suggested to be the result of the nocturnal nature of mice, as the heat loss measurements were taken at night and feed intake was measured during a 24-hr period. Despite a greater feed intake in the MH mice, they were leaner than ML mice with a $40 \%$ difference in total body fat percentage. Additionally, the MH mice had significantly larger livers and hearts than the ML mice.

Mousel et al. (2001) compared mice of the MH, MC, and ML lines for locomotor activity and core body temperature. Over a period of $3 \mathrm{~d}$, physical activity and core body temperature data were collected using implanted transmitters. They found the MH mice 
to be two times more active than the ML mice, with the MC mice intermediate to them. They estimated that approximately $35 \%$ of the difference in feed intake and heat loss between the selected lines could be explained by locomotor activity. They also noted that the $\mathrm{MH}$ mice had, on average, a $0.51^{\circ} \mathrm{C}$ greater core body temperature than ML mice. The correlation between physical activity and body temperature was observed to be 0.43 . Mousel et al. (2001) concluded that heat loss or feed intake selection changes the level of locomotor activity in a population of animals. They noted that part of physical activity is wasted energy and can be reduced, but whether or not selection for reduced physical activity to successfully reduce maintenance requirements is not known.

Kgwatalala and Nielsen (2004) studied the MH, MC, and ML mice for feed intake, body composition, and organ weights when reared at 12,22 , and $31^{\circ} \mathrm{C}$. This study was organized to determine, if any, line $\mathrm{x}$ environment interactions. They found no line $\mathrm{x}$ environment interactions for any traits measured. Mice in the hottest environment consumed the least amount of feed but were the heaviest. Overall, MH mice consumed $13 \%$ more feed than the ML mice throughout that latter parts of the feed intake trial. Confirming past results, MH mice were also leaner than ML mice. However, there were no line differences for liver weight. Kgwatalala and Nielsen (2004) conclude that, because there was no line $\mathrm{x}$ environment interactions, selection to reduce maintenance requirements will not produce animals with less ability to cope with various environmental temperatures.

It's been consistently confirmed that selection for low heat loss produces more efficient animals, but whether or not this is an increase in both growth and maintenance efficiency needed to be determined. Eggert and Nielsen (2006) used the Nebraska heat 
loss lines to estimate feed costs for gain and maintenance and to determine whether selection had changed them. To test this, mice were assigned diets of ad libitum, $80 \% \mathrm{ad}$ libitum, or $60 \%$ ad libitum intake at $21 \mathrm{~d}$ of age, and body composition was also determined at that time by dual x-ray densitometry. Following a 28-d feed intake trial, dual x-ray densitometry was used again to determine body composition. Three separate approaches were used to analyze the data and estimate partial costs of maintenance and gain. Following this, Eggert and Nielsen (2006) determined that divergent selection for heat loss had changed costs for maintenance but not for lean or fat gain.

Divergent selection for heat loss in the Nebraska lines of mice has shown to have an effect on other traits including feed intake, organ mass, physical activity, and body composition. Differences between lines in these associated traits have been shown to explain some, but not all, variation in maintenance requirements for mice. This brings to question whether or not there are line differences at the very basic cellular level, specifically the mitochondria.

\section{Mitochondrial Systems}

Mitochondrial structure and basic functional role has been studied since the 1950 's. Because of this, the mitochondrion is one of the earliest and most studied cellular organelles due in part to its relative ease of extraction and abundance. A single rat liver cell can contain more than 1,000 mitochondria, making up $22 \%$ of the hepatic cytoplasmic volume (Lehinger, 1970). Often nicknamed the "power plant" of the cell, mitochondria are the main site of oxidative phosphorylation, creating an energy source for the cell in the form of adenosine tri-phosphate (ATP). The unique dual membrane of 
the mitochondrion is key to its functional ability to create energy (Lehinger, 1970). The basic structure of a hepatic mitochondrion is shown in Figure 2.

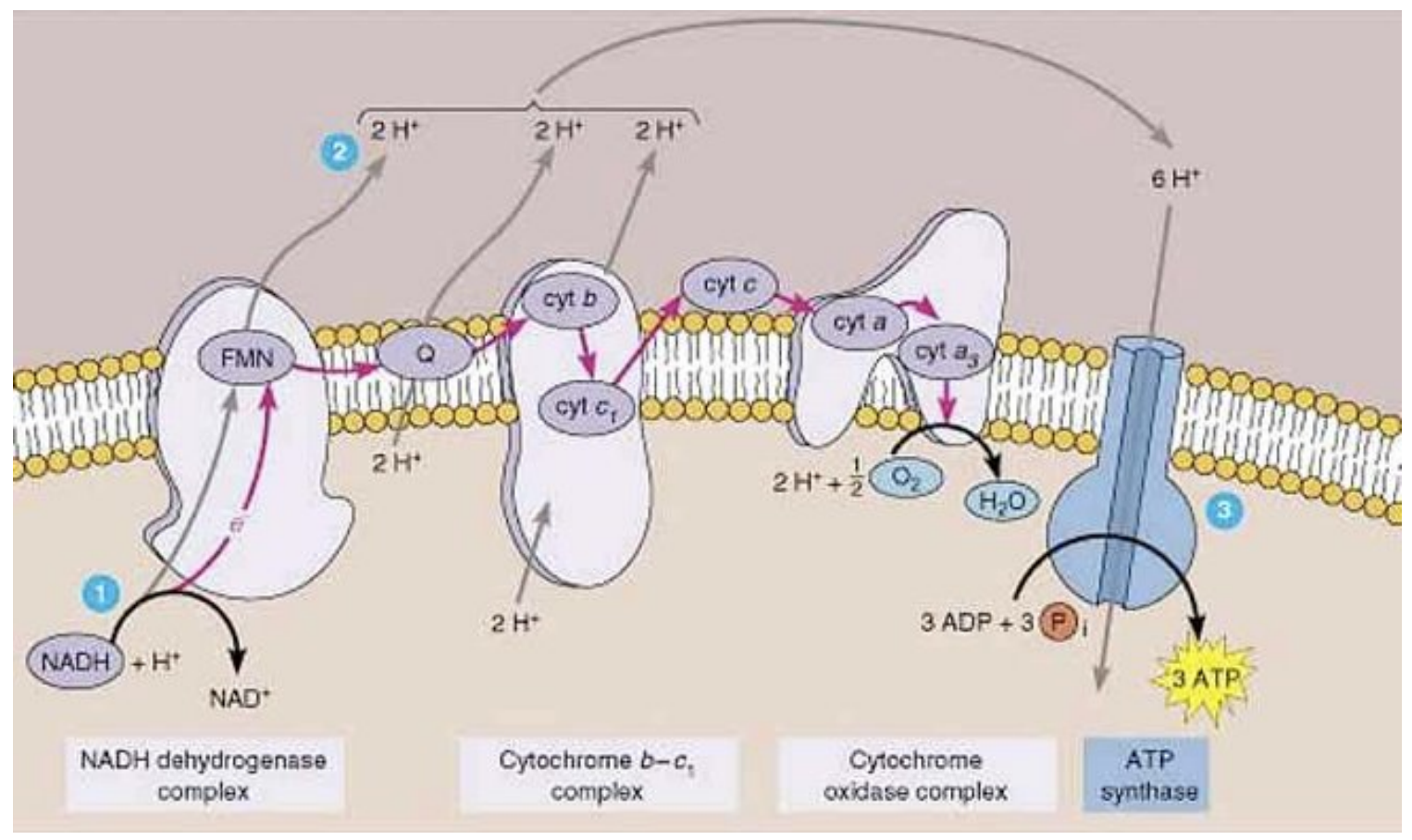

Figure 2. The inner membrane of the mitochondria and the electron transport chain complexes (Copyright 2001, Benjamin Cummings).

The outer membrane of the mitochondrion is smooth, and the inner membrane contains several folds called cristae. Within these cristae are proteins that are essential to electron transport, proton pumping, and oxidative phosphorylation, key steps to the formation of ATP. The process of creating ATP begins with a series of proteins known as the electron transport chain. The citric acid cycle creates a source of "electron donors" that initiate electron transport activity. When an electron donor comes into contact with the first inner-membrane protein it "donates" two of its electrons. These electrons are transported from one complex to the next. In order to balance out the negative charge of the electrons, positively charged hydrogen ions $(\mathrm{H}+)$ are passed from the mitochondrial matrix to the inner membrane space. Oxygen serves as the final electron acceptor, 
combining two $\mathrm{H}+$ to form water $\left(\mathrm{H}_{2} \mathrm{O}\right)$. As electron transport chain activity proceeds, a proton gradient begins to form with the inner membrane space containing a higher concentration of $\mathrm{H}+$ than the matrix (Lehinger, 1970).

ATP-synthase is another inner membrane protein, and as its name implies, it is the site of ATP synthesis. It functions with electron transport chain activity and the formation of the $\mathrm{H}+$ ion gradient. By actively transporting in $\mathrm{H}+$ back into the mitochondrial matrix, enough energy is acquired to combine adenosine di-phosphate (ADP) with inorganic phosphate $\left(\mathrm{P}_{\mathrm{i}}\right)$ forming ATP (Lehinger, 1970). Electron transport chain activity and ADP phosphorlyation are two separate reactions, but since they are dependent on one another they are referred to as coupled reactions. However, inefficiencies in either of the two reactions cause uncoupling. Brand et al. (1994) suggested that these two processes are never fully coupled in either isolated mitochondria or mitochondria in the natural cellular environment, and as a result, oxidative phosphorylation is often an inefficient process.

The majority of uncoupling occurs as a result of uncoupling proteins (UCPs) and slippage in the electron transport chain. Uncoupling proteins are membrane-bound $\mathrm{H}+$ trans-locaters that permit the transfer of $\mathrm{H}+$ from the inner-membrane space back into the mitochondrial matrix. This transfer does not aid to the function of ATP synthase and is thus detrimental to the process of oxidative phosphorylation. To make up for this, higher levels of electron donors and oxygen must be consumed to form the same amount of ATP (Ježek et al., 2004). The process involving UCPs is known as "proton leak", and as a result generates heat, not ATP. 
Another form of uncoupling is known as "proton slip". This slippage occurs as a result of malfunction within the electron transport chain when proton pumps are not functioning at full capacity. During a slippage event, protons are not transported across the inner membrane. As a result of this, the necessary proton gradient for ATP synthesis is not attained, and again an above normal amount of electron donors and oxygen must be consumed (Ricquier and Bouillaud, 2000). Higher rates of oxygen consumption result in the generation of reactive oxygen species (ROS) such as hydrogen peroxide $\left(\mathrm{H}_{2} \mathrm{O}_{2}\right)$. Boveris and Chance (1973) estimated that $2-4 \%$ of the total amount of oxygen consumed by mitochondria is converted to ROS instead of $\mathrm{H}_{2} \mathrm{O}$. If ROS are not metabolized by antioxidants, damage to critical biomolecules such as DNA, lipids, and proteins may occur. The processes and inefficiencies of the mitochondria make them a logical starting point to the study of system-wide energy creation and utilization of the cell and animal.

\section{Measuring Mitochondrial Efficiency}

Mitochondrial respiration and degree of coupling can be quantified with the aid of a Clark-type oxygen electrode. An oxygen saturated buffer and a known concentration of mitochondria are placed into the reaction chamber of the electrode. Following this, addition of various exogenous substrates will begin electron transport chain and ATPsynthase activities. As the mitochondria begin to respire, the oxygen concentration within the chamber will begin to decrease. The rate at which oxygen is consumed throughout the various steps in the process is a measurement of the degree of coupling in the 
mitochondrial sample, and thus how efficiently they are creating ATP (Hansatech Instruments, 2000).

The first substrate addition to the chamber creates a source of electron donors. Following this, a slow rate of oxygen consumption is observed, known as State 2 respiration. Once a pre-determined amount of oxygen has been consumed, exogenous ADP is added to the chamber. The ADP addition initiates ATP-synthase activity and oxygen is rapidly consumed, referred to as State 3 respiration. After all of the exogenous ADP has been phosphorylated, the mitochondria enter State 4 respiration until all of the oxygen in the chamber is consumed (Petersen, 1998).

Mitochondrial samples from the same animal and between animals are compared by the differences in each of the states of respiration. These rates are then used to calculate measures of efficiency in oxidative phosphorylation. The respiratory control ratio (RCR) is a measurement of the degree of uncoupling in the sample of mitochondria. Dividing the slope of State 3 respiration by the slope of State 4 respiration yields the RCR; a larger value indicates a greater degree of coupling, and thus efficiency. The other measurement of efficiency from the electrode output is the ADP:O ratio, attained by dividing the known amount of moles of ADP added to the chamber by the moles of oxygen consumed during State 3. Again, a larger value indicates a more efficient process since more ATP is being generated with less consumption of oxygen (Petersen, 1998). 
Biological Reasoning for Mitochondrial Uncoupling and UCP activity in the Nebraska Heat Loss Selection Lines

In a review article, Brown (1992) hypothesized some biological reasons for leaks and slips within the mitochondrial membrane. He stated that although leaks and slips cause a significant wastage of free energy, they might be an unavoidable consequence due to the nature of the inner membrane of the mitochondrion. Because of this, leaks and slips may have some evolutionary, beneficial roles for the organism in question. One possible role Brown (1992) hypothesized was to act as a buffer between electron transport and ATP synthesis so that these processes can be independent to some degree. This would be beneficial to dispose of excess electrons or substrates without raising the ATP/ADP ratio. Another possible reason behind leaks and slips could be to vary the ratio of heat to free energy produced. This would be beneficial for an organism because it would allow them to regulate free energy production independent of essential heat production.

Ricquier and Bouillaud (2000) also discussed possible roles and benefits for mitochondrial uncoupling proteins. UCP1 is found in brown adipose tissue (BAT) and induces uncoupling of respiration that produces heat to maintain a constant body temperature. This is beneficial to both newborn animals and others experiencing a cold stress event. Ricquier and Bouillaud (2000) also commented on the roles of UCP2 and UCP3. Although poorly understood they noted that UCP2 and UCP3 may serve to regulate the production of ATP. Additionally these UCPs may control the NAD ${ }^{+} / \mathrm{NADH}$ ratio to regulate various metabolic pathways. Finally they noted that UCP2 and UCP3 
might limit the production of ROS, which have been shown to be damaging to a number of biomolecules.

McDaneld et al. (2002) investigated the role of UCP1 expression in the previously described Nebraska heat loss selection lines of mice. In two independent experiments, it was determined that ML mice had a 93\% greater concentration $(\mathrm{P}<0.05)$ of UCP1 in BAT than MH mice. This was unexpected because UCP1 creates mitochondrial inefficiency with an increase in heat loss. One would expect that the inefficient MH mice, producing upwards of $50 \%$ more heat than the ML mice, would exhibit a greater concentration of UCP1.

\section{Variation of Mitochondrial Respiration within Species}

Mukherjee et al. (1970) were some of the first to investigate mitochondrial respiration in livestock species. Day-old chicks from White Leghorn (WL), White Rock (WR), and $\mathrm{F}_{1}$ hybrid (WL $\mathrm{x}$ WR) lines were sacrificed, their livers were removed, and mitochondria were isolated. WR chicks were the heaviest, with WL $x$ WR intermediate to the parental breeds. With a Clark-type oxygen electrode, oxygen uptake was measured in units of Uatom $\mathrm{O}_{2} / \mathrm{mg} \mathrm{N} / \mathrm{min}$. WR chicks had the greatest oxygen uptake and the $\mathrm{F}_{1}$ hybrid was intermediate to the purebreds. There were no line differences for mitochondrial protein concentration. Mukherjee et al. (1970) also mixed equal parts of mitochondrial isolates from the purebreds and compared its oxygen uptake to the $F_{1}$ hybrid. They found no differences between the purebred mitochondrial mixture and the 
WL $x$ WR cross. The authors noted that breed differences for mitochondrial respiration did exist, and this could be a useful tool for in vitro selection of specific crosses.

Brown et al. (1986) investigated differences in mitochondrial traits between two breeds of chicken. Mitochondria were extracted from the livers of Hubbard White Mountain Cross and White Leghorn hens; then, the respiration measurements previously described were collected. Although there were no statistical breed differences, Hubbard White Mountain Cross hens tended to have greater State 3 respiration, RCR, and ADP:O. However, within breed variability of these traits were not correlated with production traits such as BW or egg production. Additionally, Hubbard White Mountain Cross hens had a significantly greater concentration of mitochondrial protein. The authors note that this may be due to breed differences in growth and productivity.

Brown et al. (1987) continued their investigations into mitochondrial parameters by studying inbred strains $(\mathrm{A} / \mathrm{J}, \mathrm{C} 57 \mathrm{BL} / 6 \mathrm{~J}$, and BALB/cJ) of mice. Using two different substrates (succinate and pyruvate + malate), the variations in RCR, ADP:O, and mitochondrial protein concentration were then determined. They found that the C57BL/6J mice had significantly greater RCRs (more efficient) when succinate was used as the substrate. However, C57BL/6J mice had lower mitochondrial protein concentration. They also found that BALB/cJ mice had significantly greater ADP:Os (more efficient) when pyruvate + malate was used. Although these results pose some interpretation difficulties, they indicate that variation of mitochondrial measurements between inbred strains of mice do exist. Later, when Moody et al. (1997) compared the C57BL/6J strain to the Nebraska heat loss selection lines they found it to be the closest to 
the ML line in heat loss and feed intake. This suggests the possibility of some mitochondrial traits to play a role in the maintenance requirements of an animal.

\section{The Role of Mitochondrial Components in Maintenance Requirements}

Bottje and Carstens (2009) noted that although several studies have found breed or line differences to affect mitochondrial parameters, few have investigated mitochondrial function in relation to feed efficiency (FE) or RFI. They went on to review the existing literature on such studies in an effort to assist the development of selection tools for commercial breeders.

Bottje et al. (2002) used a single genetic line of broilers in an effort to determine within line differences in mitochondrial parameters as they relate to FE. One hundred male broilers were placed in a feed intake trial, and the 8 birds displaying the highest FE (High FE) and the 8 displaying the lowest FE (Low FE) were placed in two groups, respectively, and analyzed for mitochondrial traits. After the feed intake trial, mitochondria from breast and leg tissue were isolated and respiration data were collected using two different substrates (glutamate + malate and succinate). Using a Clark-type oxygen electrode, breast and leg tissue mitochondria from High FE birds displayed greater RCRs when glutamate + malate was used as a substrate, but there were no differences in RCRs when succinate acted as the substrate. There were no group differences in ADP:Os when either substrate was used. Additionally $\mathrm{H}_{2} \mathrm{O}_{2}$ generation was measured as an indicator of electron leak. Bottje et al. (2002) found that mitochondria isolated from breast muscle from Low $\mathrm{FE}$ broilers had greater $\mathrm{H}_{2} \mathrm{O}_{2}$ production. These 
results indicate that Low FE broilers show a greater degree of uncoupling and electron leak.

Using a similar experimental design as Bottje et al. (2002), Ojano-Dirain et al. (2004) grouped Low FE and High FE broilers to investigate differences in duodenal mitochondrial parameters. Similar to Bottje et al. (2002), they found that mitochondria from High FE broilers had greater RCRs when succinate was used as a substrate. However, mitochondria from Low FE displayed higher ADP:Os when malate + pyruvate was used as a substrate. $\mathrm{H}_{2} \mathrm{O}_{2}$ production was also measured, and they found that Low FE broilers had greater $(\mathrm{P}=0.08)$ basal electron leak when succinate was used as a substrate. These results agreed with several of those from Bottje et al. (2002) and confirmed that mitochondrial parameters have a significant role in the feed efficiency of an animal.

Kolath et al. (2006) set out to determine the relationship of mitochondrial parameters to RFI in a group of Angus steers. Forty Angus steers were place on a feed intake trial, and 9 showing the most negative RFI (Low RFI) and 8 with the most positive RFI (High RFI) were sacrificed for experimentation. Mitochondria from skeletal muscle were isolated and analyzed using the similar methods as Bottje et al. (2002) and OjanoDirain (2004). Low RFI steers showed greater RCRs and ADP:Os when either glutamate or succinate was used as a substrate. Interestingly, Low RFI also had a greater rate of $\mathrm{H}_{2} \mathrm{O}_{2}$ production on average. However, when $\mathrm{H}_{2} \mathrm{O}_{2}$ production was expressed as a ratio to respiration rate, there were no group differences and hence, no differences in electron leak. The authors note that there seems to be differences in mitochondrial respiration between RFI groups of steers. 
Since these studies relating mitochondrial parameters to feed efficiency traits were reported, other authors have continued research into the sub-cellular network contributing to economically important production traits in laboratory and livestock species. Sharifabadi et al. (2012) were able to study the activities of the various mitochondrial complexes and relate them to different feed efficiency traits in fat-tailed Ghezel lambs. For this study, 25 lambs from the same sire were placed on a feed intake trial and were grouped according to high and low RFI and high and low FCR. The lambs were slaughtered and mitochondria were isolated from skeletal muscle. After analyzing the RFI group it was determined that low RFI lambs had greater activity at all 5 membrane complexes studied. When analyzing the FCR group they determined that low FCR lambs had greater activity at complexes III, IV, and V. Sharifabadi et al. (2012) noted that including information about mitochondrial complexes may be useful to breeding programs selecting animals for feed efficiency.

McDonald et al. (2009) investigated the differences in mitochondrial parameters between the heat loss selection lines previously defined. Mature male mice $(n=197)$ from all 3 replicates of Generation 58 were analyzed. They found the MH mice to consume $29 \%$ more feed than ML mice when compared to the MC mean, confirming the results of others (Nielsen et al., 1997 a, b; Mousel et al., 2001; Moody et al., 1997; Kgwatalala and Nielsen, 2004; and Eggert and Nielsen, 2006). They found that the livers of MH mice were $13 \%$ larger than ML mice. Next, mitochondria were isolated and respiration data were calculated using a Clark-type oxygen electrode. ML mice had RCRs that were on, on average, $8 \%$ greater than the $\mathrm{MH}$ mice, but this was not statistically significant $(\mathrm{P}=0.14)$. Additionally, $\mathrm{ML}$ mice displayed ADP:Os that were $20 \%$ greater 
than $\mathrm{MH}$ mice $(\mathrm{P}=0.03)$. However, there was no correlation between ADP:O and feed intake per BW. It was concluded that although there were line differences in mitochondrial efficiency, it was not a means of explaining variation in maintenance requirements resulting from divergent selection in heat loss.

\section{Summary}

The reviewed literature has shown variation among breeds or lines and within breed or line for feed intake, feed efficiency and conversion, and heat loss. Many researchers have taken advantage of this variation for selection experiments in an effort to change the maintenance requirements of a group of animals. One such experiment was performed and maintained at the University of Nebraska-Lincoln where Nielsen divergent selection for heat loss in mice and successfully created large differences in feed intake and maintenance requirements have occured. Since then, others have identified sub-traits further explaining this variation in energy requirements including body composition and locomotor activity. Mitochondria are sub-cellular components essential to the production of $90 \%$ energy used by the cell. With this, analyzing the differences of mitochondrial energy production efficiency may serve as a starting point in analyzing system-wide differences of efficient livestock production. 
Materials and Methods 
Mice.

Mice used in this study were from the heat loss selection experiment as previously described by Nielsen et al. (1997a). The basis of all of the lines was a 4-way cross base population created from outbred lines. The generation interval was $15 \mathrm{wk}$, and each generation had 3 replicates separated by $5 \mathrm{wk}$. The heat loss phenotype used for selection was measured on males through direct calorimetry. Divergent selection created 2 lines: MH- high heat loss and ML- low heat loss. A third line (control), MC, was maintained without selection. Three lines with 3 independent replicates each yielded 9 unique lines.

Throughout the initial selection phase, replacement breeding animals were selected from the previous generation's 16 litters. After 16 generations, heat loss measurements and selection stopped, and the lines were expanded to 26 litters per linereplicate-generation through Generation 41. At Generation 42, McDonald and Nielsen (2007) used identical methods as previously described to renew selection through Generation 51. After this, selection ceased again, and numbers of line-replicategeneration litters were expanded to 24 for the $\mathrm{MH}$ and ML lines and 23 litters for the MC lines.

For the present study, 12-wk-old male mice were randomly chosen, one per litter, from the ML, MC, and MH lines starting with Generation 67 Replicate 3 through Generation 73 Replicate 2. Table 1 reports the numbers of mice by generation, replicate and line providing BW, feed intake (Feed), liver weight (LW), percent fat (Fat \%) and mitochondrial respiration (Mito.) data. 
Table 1: Number of animals used in data analysis by Generation, Replicate, and Line

$\begin{array}{llllllll}\text { Gen. } & \text { Rep. } & \text { Line } & \text { BW } & \text { Feed } & \text { LW } & \text { Fat \% } & \text { Mito. }\end{array}$

\begin{tabular}{|c|c|c|c|c|c|c|c|}
\hline 67 & 3 & ML & 10 & 10 & 10 & 10 & 10 \\
\hline 67 & 3 & $\mathrm{MC}$ & 10 & 10 & 10 & 10 & 5 \\
\hline 67 & 3 & $\mathrm{MH}$ & 10 & 10 & 10 & 10 & 4 \\
\hline 68 & 1 & $\mathrm{ML}$ & 10 & 10 & 10 & 0 & 8 \\
\hline 68 & 1 & $\mathrm{MC}$ & 10 & 10 & 10 & 0 & 8 \\
\hline 68 & 1 & $\mathrm{MH}$ & 10 & 10 & 10 & 0 & 6 \\
\hline 68 & 3 & ML & 8 & 8 & 5 & 5 & 2 \\
\hline 68 & 3 & $\mathrm{MC}$ & 8 & 8 & 7 & 7 & 4 \\
\hline 68 & 3 & $\mathrm{MH}$ & 8 & 8 & 6 & 5 & 2 \\
\hline 69 & 1 & $\mathrm{ML}$ & 8 & 8 & 8 & 8 & 4 \\
\hline 69 & 1 & $\mathrm{MC}$ & 8 & 8 & 8 & 7 & 1 \\
\hline 69 & 1 & $\mathrm{MH}$ & 8 & 8 & 8 & 7 & 2 \\
\hline 69 & 3 & $\mathrm{ML}$ & 9 & 9 & 9 & 7 & 2 \\
\hline 69 & 3 & $\mathrm{MC}$ & 9 & 9 & 8 & 8 & 3 \\
\hline 69 & 3 & $\mathrm{MH}$ & 10 & 10 & 10 & 9 & 2 \\
\hline 70 & 1 & $\mathrm{ML}$ & 15 & 15 & 14 & 15 & 13 \\
\hline 70 & 1 & $\mathrm{MC}$ & 15 & 15 & 15 & 15 & 11 \\
\hline 70 & 1 & $\mathrm{MH}$ & 13 & 13 & 13 & 11 & 5 \\
\hline 70 & 2 & $\mathrm{ML}$ & 15 & 15 & 14 & 13 & 12 \\
\hline 70 & 2 & $\mathrm{MC}$ & 15 & 15 & 15 & 15 & 11 \\
\hline 70 & 2 & $\mathrm{MH}$ & 15 & 15 & 14 & 14 & 9 \\
\hline 70 & 3 & $\mathrm{ML}$ & 14 & 14 & 10 & 10 & 9 \\
\hline 70 & 3 & $\mathrm{MC}$ & 14 & 14 & 9 & 9 & 8 \\
\hline 70 & 3 & $\mathrm{MH}$ & 14 & 14 & 9 & 9 & 5 \\
\hline 71 & 1 & $\mathrm{ML}$ & 10 & 10 & 6 & 6 & 5 \\
\hline 71 & 1 & $\mathrm{MC}$ & 10 & 10 & 7 & 7 & 5 \\
\hline 71 & 1 & $\mathrm{MH}$ & 10 & 10 & 7 & 6 & 6 \\
\hline 71 & 2 & ML & 10 & 10 & 8 & 8 & 7 \\
\hline 71 & 2 & $\mathrm{MC}$ & 10 & 10 & 9 & 9 & 8 \\
\hline 71 & 2 & $\mathrm{MH}$ & 10 & 10 & 9 & 8 & 4 \\
\hline 71 & 3 & $\mathrm{ML}$ & 10 & 10 & 6 & 5 & 2 \\
\hline 71 & 3 & $\mathrm{MC}$ & 10 & 10 & 6 & 6 & 2 \\
\hline 71 & 3 & $\mathrm{MH}$ & 10 & 10 & 8 & 7 & 2 \\
\hline 72 & 1 & ML & 8 & 8 & 7 & 5 & 3 \\
\hline 72 & 1 & $\mathrm{MC}$ & 8 & 8 & 6 & 6 & 5 \\
\hline 72 & 1 & $\mathrm{MH}$ & 8 & 8 & 7 & 5 & 4 \\
\hline 72 & 2 & $\mathrm{ML}$ & 8 & 8 & 0 & 0 & 0 \\
\hline 72 & 2 & $\mathrm{MC}$ & 8 & 8 & 0 & 0 & 0 \\
\hline 72 & 2 & $\mathrm{MH}$ & 8 & 8 & 0 & 0 & 0 \\
\hline
\end{tabular}




\begin{tabular}{|c|c|c|c|c|c|c|c|}
\hline Gen. & Rep. & Line & BW & Feed & LW & Fat \% & Mito. \\
\hline 72 & 3 & $\mathrm{ML}$ & 6 & 6 & 3 & 0 & 3 \\
\hline 72 & 3 & $\mathrm{MC}$ & 6 & 6 & 3 & 0 & 3 \\
\hline 72 & 3 & $\mathrm{MH}$ & 6 & 6 & 4 & 0 & 2 \\
\hline 73 & 2 & $\mathrm{ML}$ & 8 & 8 & 6 & 5 & 4 \\
\hline 73 & 2 & $\mathrm{MC}$ & 8 & 8 & 6 & 5 & 3 \\
\hline 73 & 2 & $\mathrm{MH}$ & 8 & 8 & 6 & 6 & 3 \\
\hline \multirow{3}{*}{ Line Totals } & $\mathrm{ML}$ & 149 & 149 & 116 & 96 & 84 \\
\cline { 3 - 8 } & $\mathrm{MC}$ & 149 & 149 & 119 & 104 & 77 \\
\cline { 2 - 8 } & $\mathrm{MH}$ & 148 & 148 & 121 & 97 & 56 \\
\hline
\end{tabular}

Table 1. Continued.

Note: Not all replications from each generation are present. This was due to experimenter breaks throughout the course of the study. Additionally, not all mice that underwent the feed intake trial have data for Fat $\%$ or Mito. This was due to either unavailability of X-ray equipment or removal of mitochondrial measurements from data analysis because they did not meet pre-determined criteria.

\section{Feed Intake Trial.}

Sampled males were weighed and placed in individual plastic cages (Ancare Corp., Waupaca, WI) at 12 wk of age. The lids for the cages were built of steel wire with one space for feed and another for a plastic water bottle. Feed (Harlan Teklad Global 2020X, Madison, WI; 19.1\% CP, 6.5\% Fat) supplied ad libitum. After weighing the feed, it was added to the lid and a weighted plexi-glass cover was placed on it in order to prevent feed spillage by mice. Feed intake was determined as the amount feed consumed during a 2-wk period. Feed "out" and feed "in" measurements were done for each week of the 2-wk period. At the end of the feed intake trial, mice were again weighed to determine grams of feed intake per gram of body weight then placed back into their individual cages until they were chosen for further data collection. 


\section{Liver Extraction}

Glassware items used throughout liver and mitochondrial extraction were soaked in $10 \% \mathrm{HCl}$ for a period of $18 \mathrm{hr}$, then rinsed with distilled water, and rinsed with deionized distilled water $\left(\mathrm{ddH}_{2} \mathrm{O}\right)$. Glassware was completely dried. The isolation buffers used throughout the experiment aided in separating out mitochondria and provided an environment with a constant $\mathrm{pH}$. Isolation Buffer A consisted of $250 \mathrm{mM}$ sucrose, 10 mM Tris-HCl, 1 mM Ethylene Glycol Tetraacetic Acid (EGTA), and $0.005 \mathrm{~g} / \mathrm{mL}$ of fatty acid free Bovine Serum Albumin (BSA). Isolation Buffer B consisted of $250 \mathrm{mM}$ sucrose, $10 \mathrm{mM}$ Tris- $\mathrm{HCl}$, and $1 \mathrm{mM}$ EGTA. Both isolation buffers were adjusted to a $\mathrm{pH}$ of 7.4, the average mammalian physiological $\mathrm{pH}$, using Tris powder. The isolation buffers were refrigerated at $4^{\circ} \mathrm{C}$ for no longer than $3 \mathrm{~d}$ to avoid bacterial growth. The respiration buffer was made fresh on the day of data collection. It consisted of $100 \mathrm{mM}$ $\mathrm{KCl}, 20 \mathrm{mM}$ sucrose, $10 \mathrm{mM} \mathrm{KH} \mathrm{PO}_{4}, 5 \mathrm{mM}$ HEPES, $2 \mathrm{mM} \mathrm{MgCl} 2-6 \mathrm{H}_{2} \mathrm{O}$, and $1 \mathrm{mM}$ EGTA. The respiration buffer was then adjusted to a $\mathrm{pH}$ of 7.2, the mammalian $\mathrm{pH}$ during respiration.

Prior to data collection, a centrifuge (Sorvall RC5C, Dupont Company; Newton, CT) was turned on and allowed to cool to $4^{\circ} \mathrm{C}$. Before liver extraction; six 10-mL plastic centrifuge tubes (Sarstedt Inc., Newton, NC), four 50-mL beakers, two 15-mL glass Potter-Elvhjem tubes, 1 glass stir rod, 1 rubber policeman, and 1 teflon pestle were placed on ice. Two mice were euthanized at a time via cervical dislocation. The livers were removed and transferred to separate $50-\mathrm{mL}$ beakers containing Isolation Buffer A where they were rinsed 3 times with a total of $15 \mathrm{~mL}$ to remove any hair, blood, and other 
debris. The livers were weighed in $5 \mathrm{~mL}$ of Isolation Buffer A to obtain a measurement of $g$ liver per $g$ of body weight and minced into small pieces.

\section{Isolation of Mitochondria}

The minced livers were transferred to chilled Potter-Elvhjem glass tubes for homogenization. A teflon pestle was secured into an overhead stirrer (Wheaton Science Products, Millville, NJ) then the livers were homogenized at 4,000 rpm for 4 strokes. Figure 3 depicts this homogenization process.

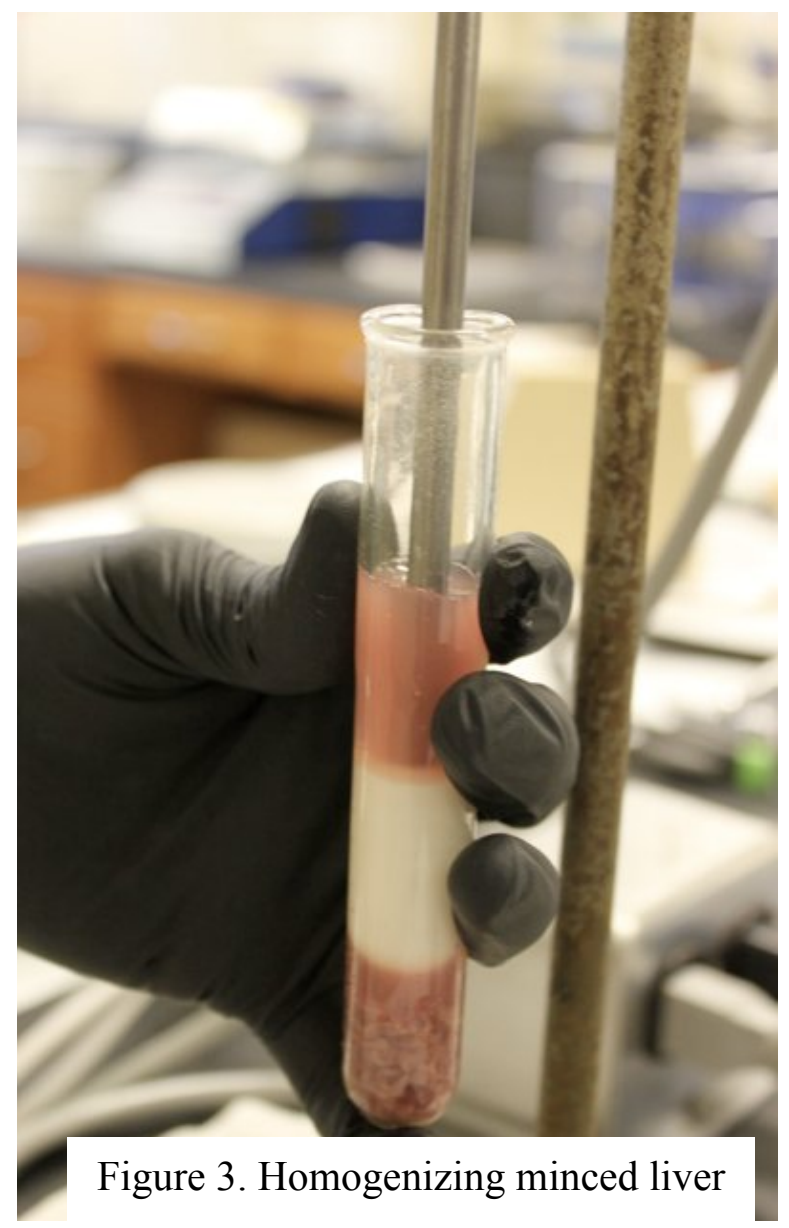


The homogenates were poured into centrifuge tubes and brought to a final volume of $10 \mathrm{~mL}$ with Isolation Buffer A. Throughout the centrifugation process lipids condense at the top of the liquid portion of the homogenate. If the lipids come into contact with the mitochondria they can cause uncoupling so they were removed with Kimwipes (Kimberly-Clark, Mississauga, Ontario, Canada). In the first centrifugation step, tubes were spun at $700 \mathrm{xg}$ for $10 \mathrm{~min}$ at $4^{\circ} \mathrm{C}$. This step pulls the cell membrane and other organelles to a pellet at the bottom, leaving the mitochondria suspended in the supernatant. The supernatants were transferred to a second centrifuge tube using chilled Pasteur pipettes. These tubes were then spun at $7500 \mathrm{x}$ g for $10 \mathrm{~min}$ at $4^{\circ} \mathrm{C}$. This step condensed the mitochondria into a pellet (Figure 4) and the supernatant was discarded. Occasionally remaining red blood cells would also be mixed in with the mitochondria. If this were the case, a rubber policeman was used to scrape around the red blood cells and mitochondria were flushed into a third centrifuge tube with Isolation Buffer B. In either case, the mitochondria were re-suspended in $5 \mathrm{~mL}$ of Isolation Buffer B with a chilled glass stir rod. Next, the mitochondria were centrifuged again at $7500 \mathrm{x} g$ for $10 \mathrm{~min}$ at $4^{\circ} \mathrm{C}$. The supernatant was again discarded and $0.5 \mathrm{~mL}$ of Isolation Buffer B was added. The mitochondria were pipetted in and out of a pipette tip until the solution was uniformly mixed. 


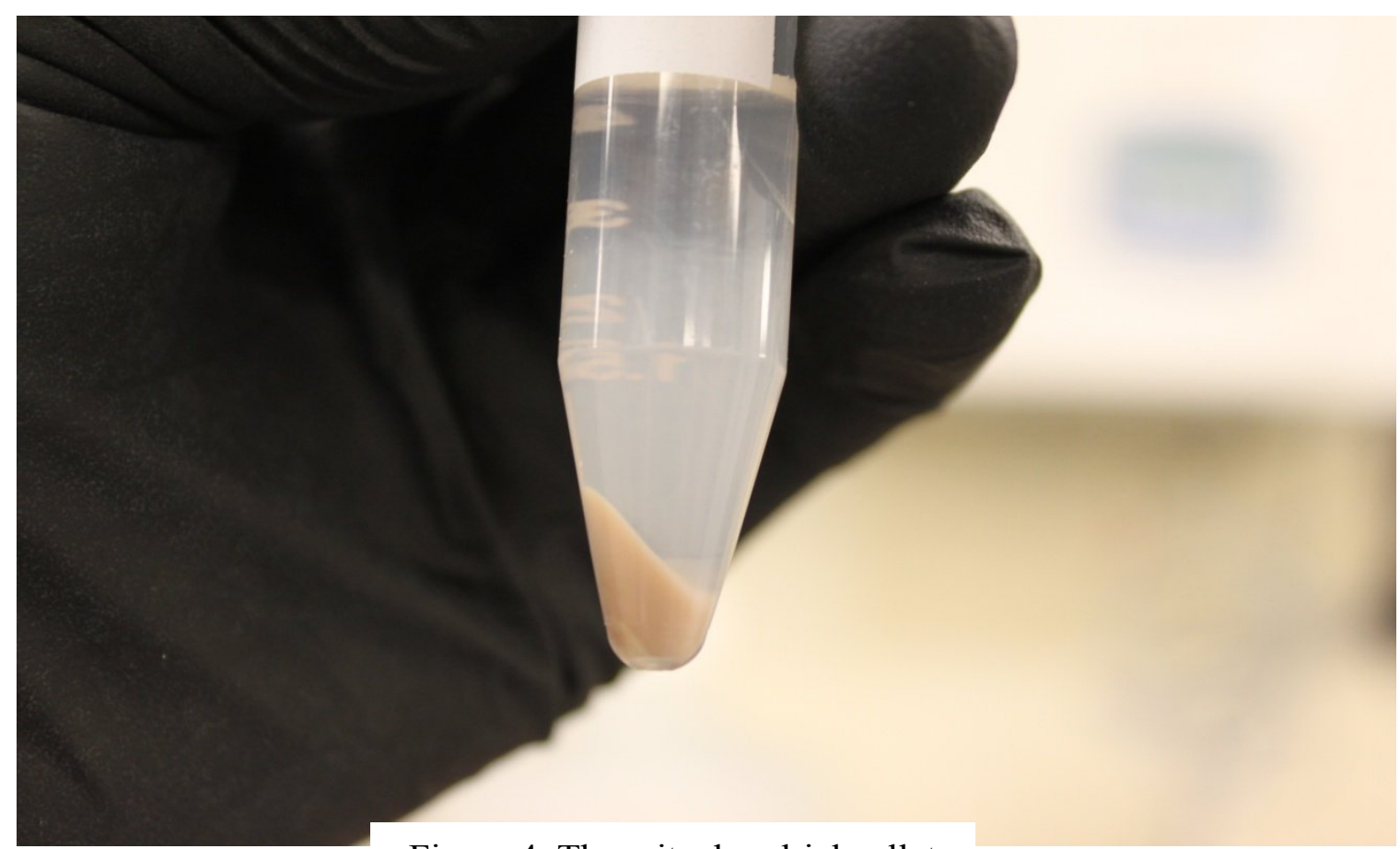

Figure 4. The mitochondrial pellet

\section{Determination of Percent Fat}

After the mice were euthanized, body composition was determined during the centrifugation steps using a PIXI-mus densitometer (Lunar Corp., Madison, WI). The mice carcasses were individually placed on plastic trays (Lunar Corp., Madison, WI) to maintain a constant position during the $\mathrm{x}$-ray process. The densitometer saved the percent fat of the mouse to a computer and it was later retrieved for data analysis.

\section{Spectrometry of Mitochondrial Sample}

A Spectra-Max spectrophotometer (Molecular Devices Corp., Sunnyvale, CA) was used to determine the protein concentration of the mitochondrial sample. A BSA standard curve and its line equation estimated protein concentration of the mitochondrial sample from its absorbance. The BSA standards (Thermo Scientific, Rockford, IL) were diluted according to company protocol, setting the x-axis at $0 \mathrm{mg} / \mathrm{mL}, 0.5 \mathrm{mg} / \mathrm{mL}, 0.75$ 


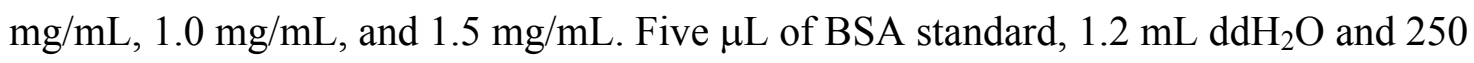
$\mu \mathrm{L}$ of Bradford reagent (Sigma, St. Louis, MO) was added to a 1.5-mL Eppendorf tube for each standard. The tubes were vortexed for $5 \mathrm{~s}$ and $300 \mu \mathrm{L}$ of the solution was added to 4 wells on a micro-plate (BD Biosciences, Sparks, MD). The 4 measurements of absorbance at $595 \mathrm{~nm}$ were averaged for each sample and the final equation was:

$$
\mathrm{Y}=0.148+0.099 \mathrm{X}
$$

where $\mathrm{Y}$ is the average absorbance of the sample then, solving for $\mathrm{X}$, protein concentration is determined in $\mathrm{mg} / \mathrm{mL}$.

To determine mitochondrial protein concentration, $5 \mu \mathrm{L}$ from the mitochondrial

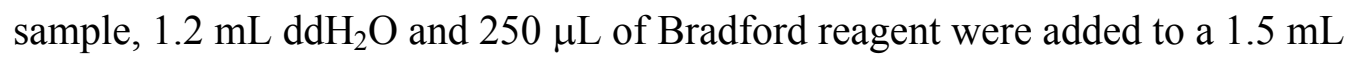
Eppendorf tube, vortexed, and allowed to reach room temperature. With the previous equation, the average absorbance estimated protein concentration.

\section{Clark-type Oxygen Electrode}

A Clark-type oxygen electrode (Rank Brothers Ltd., Cambridge, England) is a device that measures the oxygen concentration of a solution by means of an oxidationreduction reaction. The base of the electrode has a silver ring that acts as the anode and a platinum cathode. Forty $\mu \mathrm{L}$ of $3 \mathrm{M} \mathrm{KCl}$ was added to the anode then a $2.5 \times 2.5-\mathrm{cm}$ piece Kimwipe connected the anode to the cathode, forming the necessary salt bridge. A $2.5 \mathrm{x}$ 2.5-cm square of teflon was placed over the Kimwipe, a small O-ring was secured to the electrode base and the upper reaction chamber was tightened to the base. The base of the 
electrode is attached to a magnetic component that keeps the solution in the reaction chamber thoroughly mixed. Figure 5 shows a typical Clark-type oxygen electrode.

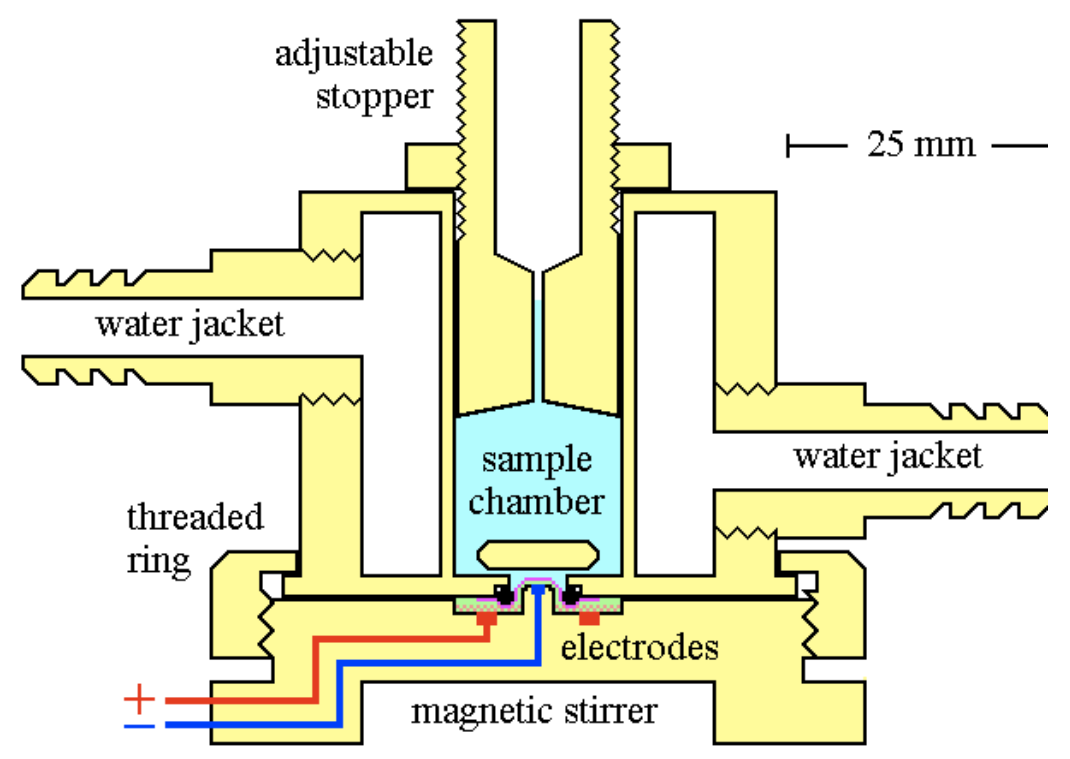

Figure 5. An example of a Clark-type oxygen electrode ("Molecular Biology" Dr. John Illingworth).

A circulating water bath (Polyscience Corp., Niles, IL) ensured the reaction chamber would be maintained at the average body temperature of a mouse, $37^{\circ} \mathrm{C}$. The electrode determines the percent oxygen of a solution but needs to be calibrated to the appropriate range of 0 to $100 \%$. To do this, the respiration buffer was supplied with an air hose for $10 \mathrm{~min}$, completely oxygenating it. Next, $1 \mathrm{~mL}$ of oxygenated respiration buffer was added to the reaction chamber with a magnetic "flea" stirrer. The reaction chamber was capped off with a stopper so that atmospheric oxygen would not interfere with the electrode's reading. The reading of the oxygen electrode was relayed to a computer via a data logger (Pico Technology, Cambridgeshire, UK) that enabled the respiration data to be saved to a computer for later analysis. The electrode was adjusted to $100 \%$ to calibrate 
it as complete oxygen saturation. To calibrate the electrode to $0 \%$ oxygen a small amount of sodium hydrosulfite was added to the reaction chamber that completely removed the dissolved oxygen in the solution. The reaction chamber was flushed several times with $\mathrm{ddH}_{2} \mathrm{O}$ and $1 \mathrm{~mL}$ of oxygenated respiration buffer was again added to the reaction chamber until mitochondrial respiration measurements were ready to be taken.

\section{Mitochondrial Respiration Collection}

After the protein concentration of the mitochondrial sample was determined, the volume needed to attain $1 \mathrm{mg}$ mitochondria/mL of solution within the reaction chamber was calculated. Rotenone acts as a mitochondrial inhibitor and blocks the activity of the Complex I receptor to attain a more accurate assessment of the electron transport chain. The appropriate volume of mitochondrial sample, $5 \mu$ moles of Rotenone, and enough respiration buffer to attain a final volume of $1 \mathrm{~mL}$ were added to the reaction chamber. The oxygen concentration of the reaction chamber could be seen in a real-time graph on the computer that was then saved for later analysis. Once the reading on the electrode and computer was stable, 10 mmoles of succinate was added to the chamber to initiate electron transport chain activity and State 2 respiration. When the reading on the computer displayed $85 \%$ oxygen, $1.67 \times 10^{-4}$ moles of ADP was added to the reaction chamber to begin State 3 respiration. Eventually all of the exogenous ADP was consumed and the reaction entered State 4 respiration until the oxygen level in the reaction chamber reached $0 \%$. Figure 6 shows a typical graph displaying the oxygen concentration of the reaction chamber throughout the course of the experiment. 
The reaction chamber was then rinsed several times with $\mathrm{ddH}_{2} \mathrm{O}$. These respiration steps were repeated 2 to 3 times for each mouse. After the day's measurements were completed the electrode was disassembled, the mitochondrial samples were discarded, and the ADP, succinate, and Rotenone were stored at $-20^{\circ} \mathrm{C}$. The Kimwipe and tephlon squares were discarded and the anode was cleaned with silver polish to remove any debris that may have built up throughout the reaction.

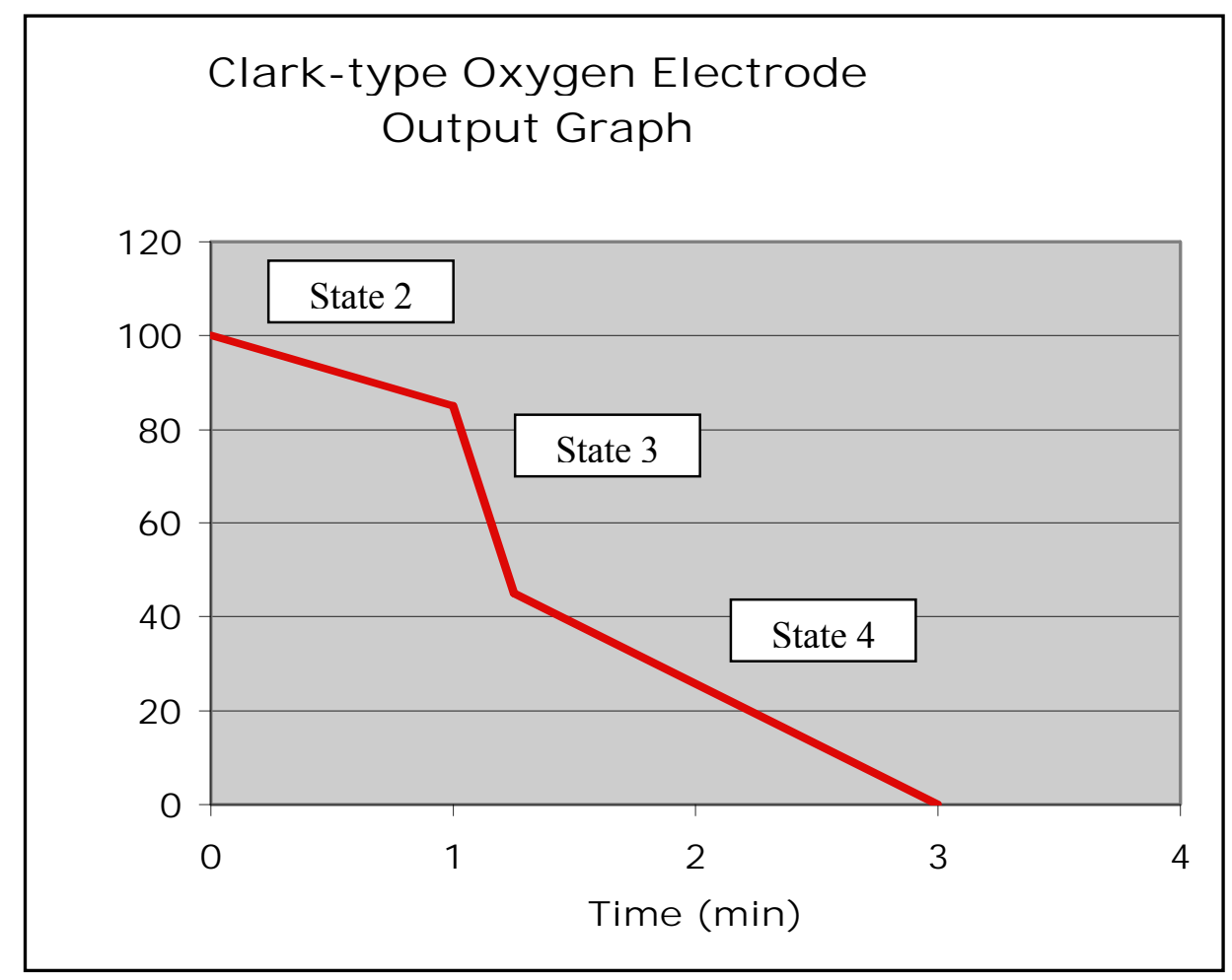

Figure 6. Clark-type Oxygen Electrode Output Graph ("Molecular Biology" Dr. John Illingworth).

\section{Analysis of Respiration Results}

There are several variables that can be calculated from the oxygen consumption output graph. But first, the scale of percent oxygen consumed must be converted into 
moles of oxygen consumed. For this, the Beckman instruction manual (Beckman Instruments Inc., Scientific Instruments Division, Fullerton, CA) was used to determine $\mu$ moles $\mathrm{O}_{2}$ dissolved in liquid at $37^{\circ} \mathrm{C}$. With $1 \mathrm{~mL}$ of respiration buffer inside the reaction chamber there are $0.213 \mu$ moles $\mathrm{O}_{2}$ dissolved at $100 \%$ oxygen saturation so, it can be determined how many $\mu$ moles $\mathrm{O}_{2}$ are consumed per percentage oxygen consumed. For example if $35 \%$ of the oxygen in the reaction chamber were consumed over a period of $40 \mathrm{~s}$, this would convert to $0.0746 \mu$ moles of oxygen consumed as shown below:

\section{$0.213 \mu$ moles $\mathrm{O}_{2}$}

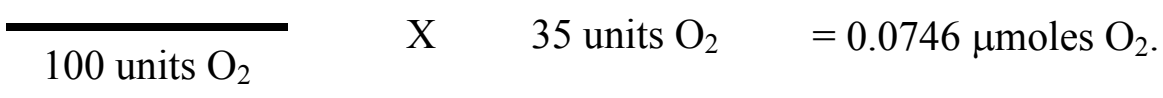

The states of respiration (States 2, 3, and 4) were each a slope function calculated from the graph. The amount of oxygen consumed was divided by the amount of time during the particular state of respiration. The respiratory control ratio (RCR) was calculated by dividing the slope of State 3 by the slope of State 4 . The ADP:O ratio is calculated by dividing the amount ADP added to the reaction chamber $\left(1.667 \times 10^{-4}\right.$ $\mu$ moles) by the $\mu$ moles $\mathrm{O}_{2}$ consumed during State 3 .

\section{Statistical Analysis}

The variables used to compare lines of mice in this study were from both the feed intake trial and the respiration data. The average BW (g) of an animal was calculated from their BW at the beginning of the feed intake trial and their BW at the end. Feed intake per body weight $(\mathrm{g} / \mathrm{g})$ was calculated by the amount of feed consumed during the 2-wk trial by the average BW of the mouse. Liver weight per body weight $(\mathrm{g} / \mathrm{g})$ was 
calculated by the weight of the liver divided by the weight of the mouse after euthanasia. Percent fat was obtained from the dual x-ray measurement. The variables obtained from the extracted mitochondria were: mitochondrial protein concentration, percent fat, States 2, 3 and 4, RCR and ADP:O.

Tests of differences between the lines in BW, feed intake per body weight, percent fat, liver weight per body weight, and mitochondrial protein concentration were derived using the MIXED procedure of SAS (SAS Institute Inc., Carey, NC) using the following model:

$$
\mathrm{y}_{\mathrm{ijkl}}=\text { mean }+ \text { line }_{\mathrm{i}}+\operatorname{rep}_{\mathrm{j}}+\text { gen }_{\mathrm{k}}+\text { line }^{*} \mathrm{rep}_{\mathrm{ij}}+\mathrm{e}_{\mathrm{ijkl}}
$$

where $y_{i j k l}$ is one of the traits listed, line $e_{i}$ is the fixed effect of line $(\mathrm{ML}, \mathrm{MC}, \mathrm{MH})$, rep $\mathrm{p}_{\mathrm{j}}$ is the random effect of replicate (rep 1, 2, or 3), gen $_{k}$ is the random effect of generation, line* rep $_{\mathrm{ij}}$ is the random interaction of line and replicate and the error term for effect of line, and $\mathrm{e}_{\mathrm{ijkl}}$ is the residual term. Orthogonal contrasts of the above traits were set up to determine both selection effects and asymmetry of selection. Selection effects were tested in a contrast statement by comparing ML vs. MH (MH-ML). Asymmetry of selection was tested by comparing the MC line with the average of the ML and $\mathrm{MH}$ lines ((ML + $\mathrm{MH}) / 2-\mathrm{MC})$ ).

For respiration traits measured multiple times per animal (State 2, State 3, State 4, RCRs, and ADP:Os), tests of differences between lines were derived using the following model:

$$
\mathrm{y}_{\mathrm{ijklm}}=\text { mean }+ \text { line }_{\mathrm{i}}+\text { rep }_{\mathrm{j}}+\text { gen }_{\mathrm{k}}+\text { line }^{*} \mathrm{rep}_{\mathrm{ij}}+\text { mouse }_{\mathrm{ijkl}}+\mathrm{e}_{\mathrm{ijklm}}
$$

where $y_{\mathrm{ijklm}}$ is one of the traits listed, line $\mathrm{i}$, rep $_{\mathrm{j}}$, gen $_{\mathrm{k}}$, line $^{*} \mathrm{rep}_{\mathrm{ij}}$, were defined in the previous model, and mouse $\mathrm{ijkl}_{\mathrm{jk}}$ is the random effect of an individual mouse. The 
orthogonal contrasts from the previous model were again used to test for effects of selection and asymmetry. If a mitochondrial sample did not display a RCR value of 2.0 or greater it was removed from the analysis. This is the threshold commonly set by experimenters that determines a viable mitochondrial sample. Repeatability was calculated as $\sigma^{2}$ mouse $/\left(\sigma_{\text {residual }}^{2}+\sigma_{\text {mouse }}^{2}\right)$.

The MIXED procedure of SAS was again used to calculate the regression of feed intake per body weight on State 2, State 3, State 4, RCR, or ADP:O. The following model was used:

$$
\text { FeedperBW } \mathrm{ijkl}_{\mathrm{ijl}}=\text { mean }+ \text { rep }_{\mathrm{i}}+\text { line }_{\mathrm{j}}+\mathrm{gen}_{\mathrm{k}}+\mathrm{bX}_{\mathrm{ijk}}+\mathrm{e}_{\mathrm{ijk} \mathrm{l}}
$$

where $\mathrm{X}_{\mathrm{ijkl}}$ represents one of the traits listed as a covariate, rep $\mathrm{p}_{\mathrm{i}}$ is the effect of replicate, line $_{\mathrm{j}}$ is the line effect, and gen $\mathrm{k}_{\mathrm{k}}$ is the generation effect.

The MANOVA function of SAS was used to calculate partial correlation coefficients of all traits. The model used was:

$$
\text { Trait }=\text { mean }+ \text { rep }_{\mathrm{i}}+\text { line }_{\mathrm{j}}+\text { gen }_{\mathrm{k}}+\text { rep}^{*} \operatorname{line}_{\mathrm{ij}}+\mathrm{e}_{\mathrm{ijk} \mathrm{l}}
$$

where traits were average BW, feed intake per BW, liver weight per BW, percent fat, mitochondrial protein concentration, average slopes of states 2,3 , and 4 respiration, average RCR and average ADP:O. Rep , line $_{\mathrm{j}}$, gen $\mathrm{k}_{\mathrm{k}}$, and rep*line $\mathrm{ij}_{\mathrm{ij}}$ are described above. 
Results and Discussion 


\section{Body Weight and Feed Intake}

Line means across all replicates and generations for average BW and feed intake per BW for the 2-wk feed intake trial are shown in Table 2. There were no selection effects $(\mathrm{MH}-\mathrm{ML})$ on average $\mathrm{BW}(\mathrm{P}=0.36)$. However, the test of asymmetry was significant $(\mathrm{P}=0.022)$. This effect was due to the $\mathrm{MC}$ mice being the heaviest, $10 \%$ heavier than the average of the selected lines. Because of this, the line effect for average BW was significant $(P=0.047)$. A graphical representation of average $B W$ is shown in Figure 7.

After 15 generations of divergent selection for heat loss, Nielsen et al. (1997b) examined the correlated responses in BW among the lines. They found that there was no significant difference between the selected lines for BW, however the MC males were $8 \%$ heavier than the selected lines. After renewed selection for heat loss, McDonald and Nielsen (2007) reported that MC males were 9\% heavier than the ML and MH males. Most recently, McDonald et al. (2009) showed that MC males were 10\% heavier than the average of the selected lines. The present study agrees with the previous studies and suggests that heat loss selection affects body weight relative to an unselected control line. 


\begin{tabular}{|c|c|c|}
\hline${ }^{\mathrm{a}}$ Line & BW $(\mathbf{g})$ & Feed Intake per BW $(\mathbf{g} / \mathbf{g})$ \\
\hline $\mathrm{ML}$ & $36.83 \pm 1.14$ & $1.57 \pm 0.04$ \\
\hline $\mathrm{MC}$ & $40.12 \pm 1.14$ & $1.70 \pm 0.04$ \\
\hline $\mathrm{MH}$ & $35.55 \pm 1.14$ & $2.22 \pm 0.04$ \\
\hline
\end{tabular}

Table 2. Average body weights \pm SE during the feed intake trial and feed intake (2-wk total) per BW for the ML, MC, and MH lines across all replicates and generations.

${ }^{\mathrm{a}}$ Line: $\mathrm{ML}=$ low heat loss, $\mathrm{MC}=$ unselected control, $\mathrm{MH}=$ high heat loss.

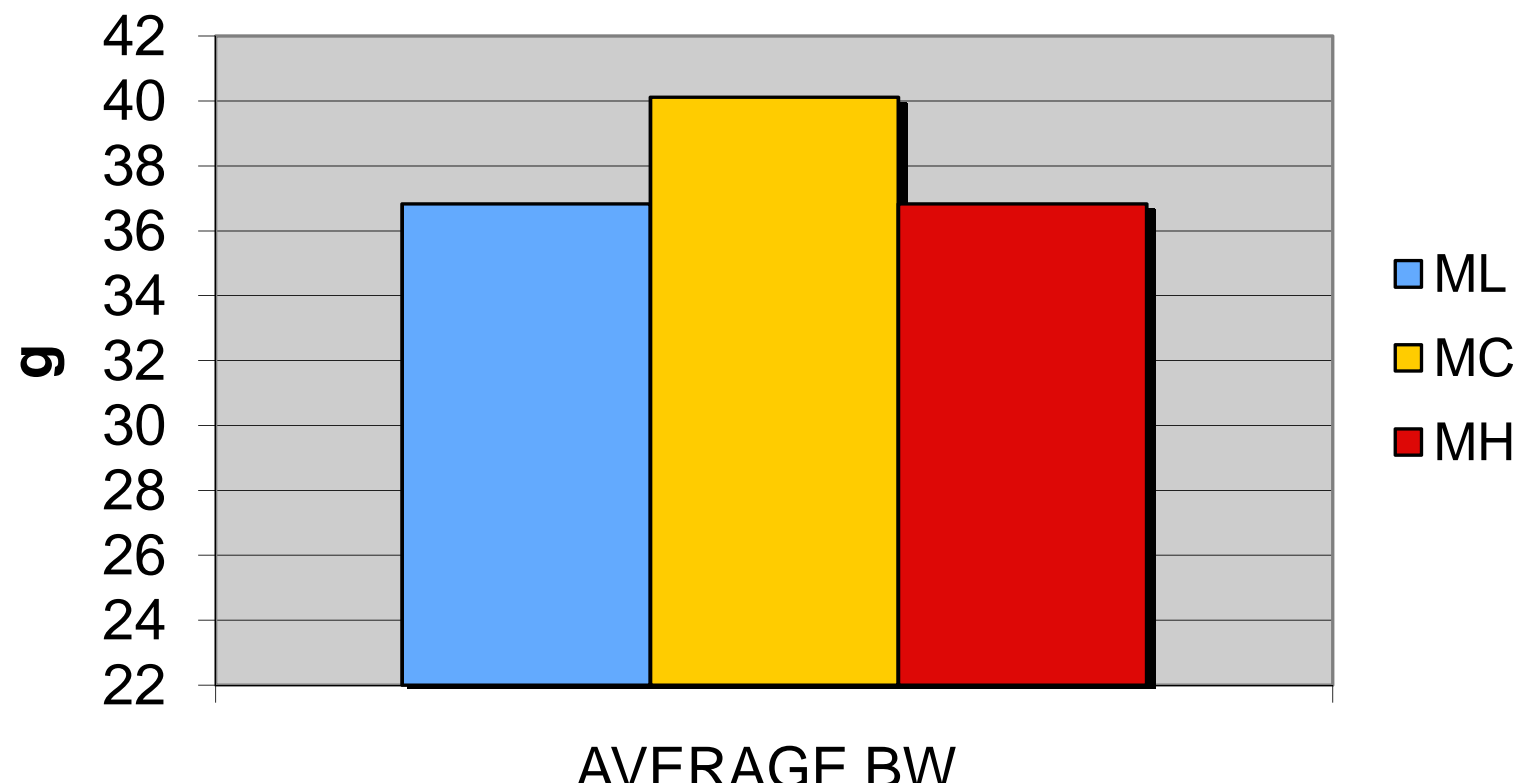

Figure 7. Average BW of low heat loss (ML), control (MC), and high heat loss $(\mathrm{MH})$ lines of mice across all generations and replicates. $\mathrm{ML}=36.8 \mathrm{~g}, \mathrm{MC}=40.1 \mathrm{~g}$, and $\mathrm{MH}=35.5 \mathrm{~g}$. Test for response to selection $\mathrm{P}=0.36$. Test for asymmetry of response $\mathrm{P}=$ 0.022 . 
Line means for feed intake per BW across all generations and replicates are also given in Table 2. The selection effects for feed intake per BW were significant $(\mathrm{P}<$ 0.0002) with the MH males consuming approximately 34\% more feed than the ML males. Additionally, asymmetry of selection was significant $(\mathrm{P}=0.012)$ as the MC males were more similar to the ML males in terms of feed intake per BW. A graphical representation of feed intake per BW is shown in Figure 8.

Following initial selection for heat loss, Nielsen et al. (1997b) reported correlated responses in feed intake. They found the $\mathrm{MH}$ males to consume $23 \%$ more feed than ML males with no differences in BW. After renewed selection for heat loss, McDonald and Nielsen (2007) found that MH males consumed 34\% more feed per BW than ML males. In the most recent study with the Nebraska heat loss lines, McDonald et al. (2009) reported the $\mathrm{MH}$ line consumed 29\% more feed per BW than the ML line. The present study agrees with others, divergent selection for heat loss has resulted in large differences in feed intake between the MH and ML lines with no differences in body weight.

\section{Body Composition and Liver Weight}

Line means across all replicates and generations for percent body fat and liver weight per BW are shown in Table 3. Selection effects for percent body fat approached significance $(\mathrm{P}=0.062)$ with the ML mice being approximately $20 \%$ fatter than the $\mathrm{MH}$ mice. The MC mice were intermediate to the selected mice and no effect of asymmetry of selection was observed $(\mathrm{P}=0.53)$. 


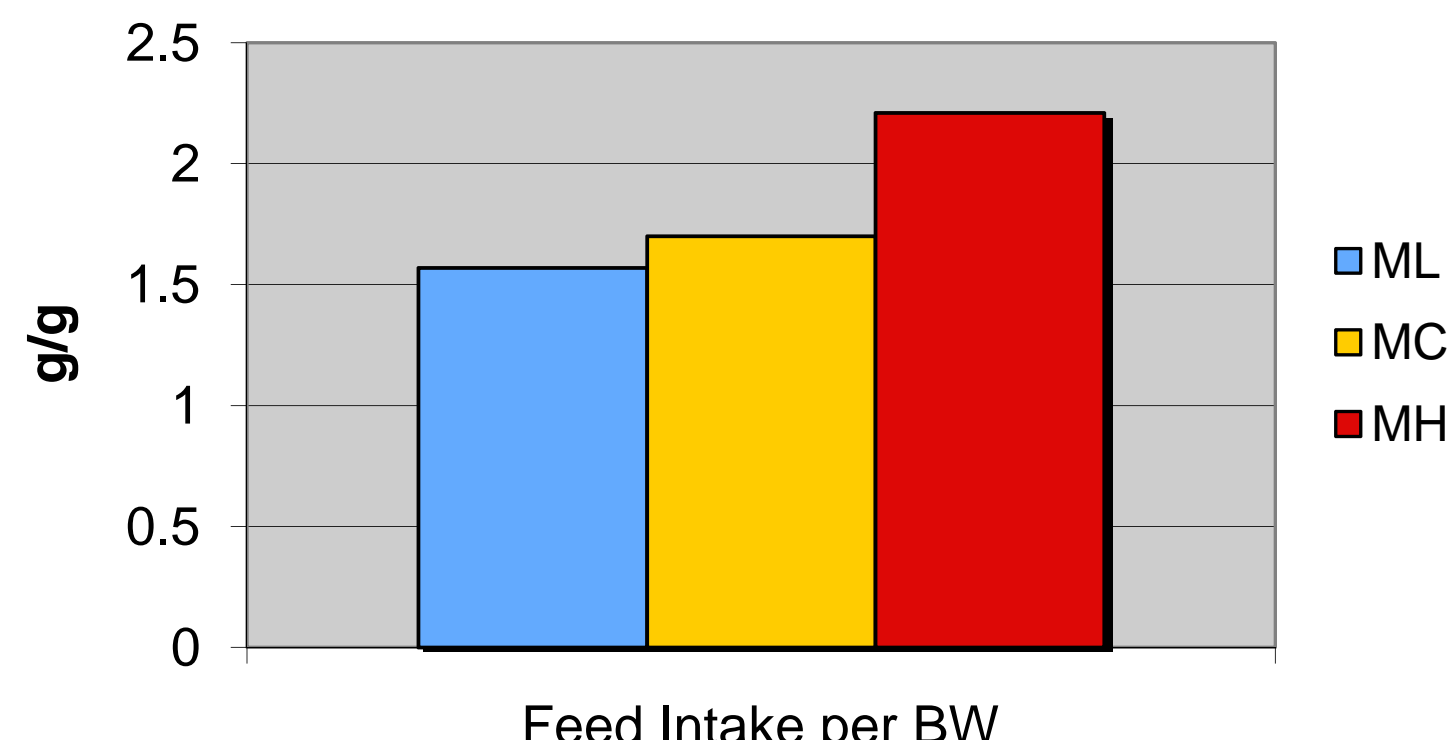

Figure 8. Average feed intake per BW of low heat loss (ML), control (MC), and high heat loss (MH) lines of mice across all generations and replicates. $\mathrm{ML}=1.57 \mathrm{~g} / \mathrm{g}, \mathrm{MC}=1.70 \mathrm{~g} / \mathrm{g}$, and $\mathrm{MH}=2.22 \mathrm{~g} / \mathrm{g}$. Test for response to selection $\mathrm{P}=0.0002$. Test for asymmetry of response $\mathrm{P}=0.012$.

\begin{tabular}{|c|c|c|}
\hline${ }^{\text {a Line }}$ & Fat\% & Liver weight per BW $(\mathbf{g} / \mathbf{g})$ \\
\hline ML & $22.5 \pm 1.4$ & $0.057 \pm 0.002$ \\
\hline MC & $21.4 \pm 1.4$ & $0.058 \pm 0.002$ \\
\hline MH & $18.5 \pm 1.4$ & $0.055 \pm 0.002$ \\
\hline
\end{tabular}

Table 3. Means $\pm \mathrm{SE}$ for percent fat and liver weight per body weight for the $\mathrm{ML}, \mathrm{MC}$, and $\mathrm{MH}$ lines across all replicates and generations.

${ }^{a}$ Line: $\mathrm{ML}=$ low heat loss, $\mathrm{MC}=$ unselected control, $\mathrm{MH}=$ high heat loss; 
After initial selection, Nielsen et al. (1997b) estimated body composition through electrical conductivity. They found that the $\mathrm{MH}$ mice were significantly leaner than the ML mice, with the MC mice intermediate. Following this, Moody et al. (1997) confirmed these results and reported that the $\mathrm{MH}$ mice had $40 \%$ less chemical fat, and hence were leaner, than the ML mice after lipid extraction. Beginning with Kgwatalala and Nielsen (2004), fat percentage in the Nebraska heat loss selection lines was measured with densitometry. Kgwatalala and Nielsen (2004) found that the ML mice were the fattest and the MC mice were intermediate to the selected lines. McDonald et al. (2009) found that the ML mice tended to be fatter than the MH mice but there were no statistical differences. Interestingly, McDonald et al. (2009) found the MC mice were not intermediate to the selected lines and were the fattest. The present study agrees with several of these prior studies, although no statistical differences were found between the selected lines for percent fat, the MC mice were intermediate. A graphical representation of fat percentage is shown in Figure 9.

After divergent selection for feed to gain in Angus bulls, Bishop et al. (1991a) reported that low feed to gain animals (more efficient) had greater amounts of subcutaneous fat. Jensen et al. (1992) concluded that bull calves displaying low REI were more efficient and were fatter. With this, Jensen et al. (1992) hypothesized that selection for low REI would yield fatter animals. These results are similar to past studies as well as the present one with Nebraska heat loss lines, and show that more efficient animals tend to be fatter. 


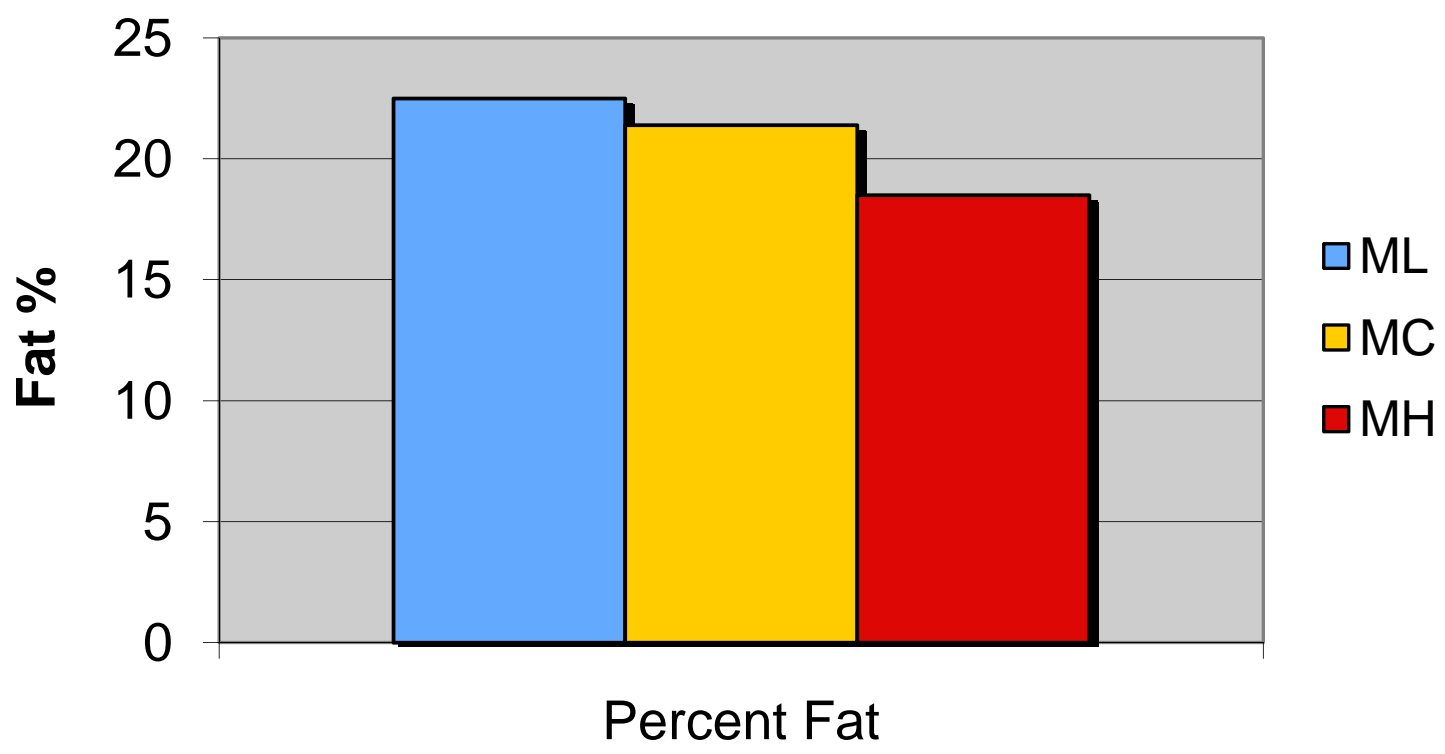

Figure 9. Means for percent fat of low heat loss (ML), control (MC), and high heat loss $(\mathrm{MH})$ lines of mice across all generations and replicates. $\mathrm{ML}=22.5, \mathrm{MC}=21.4$, and $\mathrm{MH}=18.5$. Test for response to selection $\mathrm{P}=0.062$. Test for asymmetry of response $\mathrm{P}=$ 0.53 .

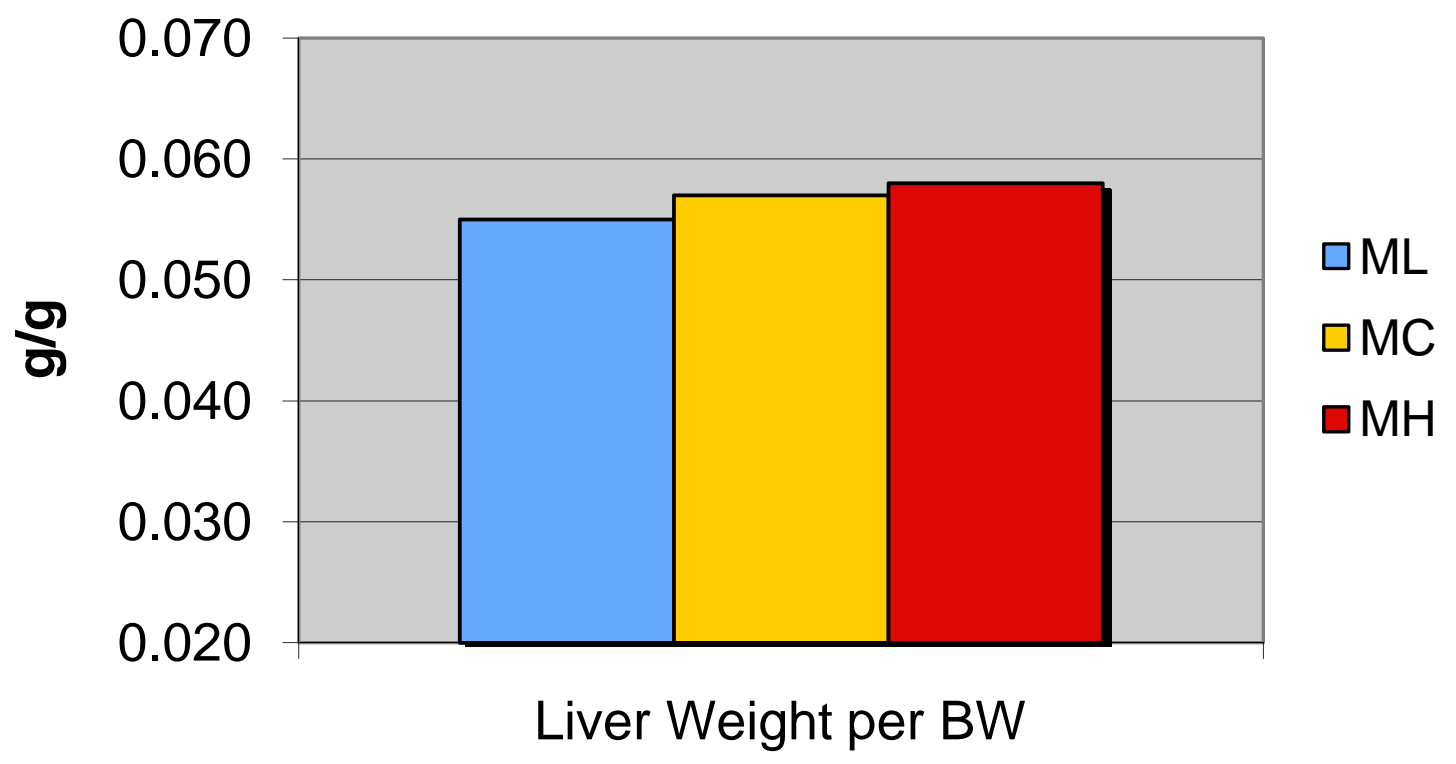

Figure 10. Means for liver weight per BW of low heat loss (ML), control (MC), and high heat loss (MH) lines of mice across all generations and replicates. $\mathrm{ML}=0.055, \mathrm{MC}=0.057$, and $\mathrm{MH}=$ 0.058 . Test for response to selection $P=0.25$. Test for asymmetry of response $\mathrm{P}=0.88$. 
Liver weight per body weight means by line across replicates and generations for the present study are presented in Table 3 . No effect of selection $(\mathrm{P}=0.25)$ was found so that $\mathrm{MH}$ and ML mice had similar liver weights when corrected for BW. Additionally, asymmetry of selection was not significant $(\mathrm{P}=0.88)$. A graphical representation of line means for liver weight per BW is given in Figure 10.

Moody et al. (1997) studied the differences in liver size between the selected lines. They reported that the MH mice had significantly larger livers than the ML mice. The results of Kgwatalala and Nielsen (2004) did not agree with Moody et al,; they found no statistical differences in liver weight per BW between the selected lines $(\mathrm{P}>0.20)$. Most recently, McDonald et al. (2009) found that the MH mice had statistically larger livers $(\mathrm{P}=0.03)$ than the ML mice and the MC mice were intermediate $(\mathrm{P}=0.45)$. Liver weight per BW is not consistently larger in the $\mathrm{MH}$ line. Knowing this, the present study confirms others who have studied that Nebraska heat loss selection lines.

When determining the maintenance requirements in beef cattle, Ferrell and Jenkins (1985) hypothesized that some variation in maintenance could be explained by variation in visceral organ mass. Although no statistical differences in liver weight were found in the present study, MH mice had the largest livers numerically.

\section{Mitochondrial Traits}

The mitochondrial traits measured in the present study consisted of: hepatic mitochondrial protein concentration, State 2 respiration, State 3 respiration, State 4 respiration, RCR, and ADP:O. Means of these traits by line are presented in Table 4. 


\begin{tabular}{|c|c|c|c|c|}
\hline${ }^{\mathrm{a}}$ Line & $\begin{array}{c}\text { Protein } \\
(\mathbf{m g} / \mathbf{m L})\end{array}$ & $\begin{array}{c}\text { State 2 } \\
\left(\mu \mathbf{O}_{2} / \mathbf{m i n}\right)\end{array}$ & $\begin{array}{c}\text { State 3 } \\
\left(\mu \mathbf{O}_{2} / \mathbf{m i n}\right)\end{array}$ & $\begin{array}{c}\text { State 4 } \\
\left(\mu \mathbf{O}_{2} / \mathbf{m i n}\right)\end{array}$ \\
\hline $\mathrm{ML}$ & $47.4 \pm 1.8$ & $-11.3 \pm 0.56$ & $-42.2 \pm 2.6$ & $-14.5 \pm 1.0$ \\
\hline $\mathrm{MC}$ & $44.3 \pm 1.7$ & $-10.8 \pm 0.58$ & $-35.5 \pm 2.7$ & $-13.9 \pm 1.0$ \\
\hline $\mathrm{MH}$ & $43.5 \pm 1.7$ & $-9.6 \pm 0.61$ & $-36.2 \pm 2.8$ & $-15.4 \pm 1.0$ \\
\hline
\end{tabular}

Table 4. Means \pm SE for mitochondrial protein, State 2, State 3, and State 4 for the ML, MC, and MH lines across all replicates and generations.

${ }^{\mathrm{a}}$ Line: $\mathrm{ML}=$ low heat loss, $\mathrm{MC}=$ unselected control, $\mathrm{MH}=$ high heat loss.

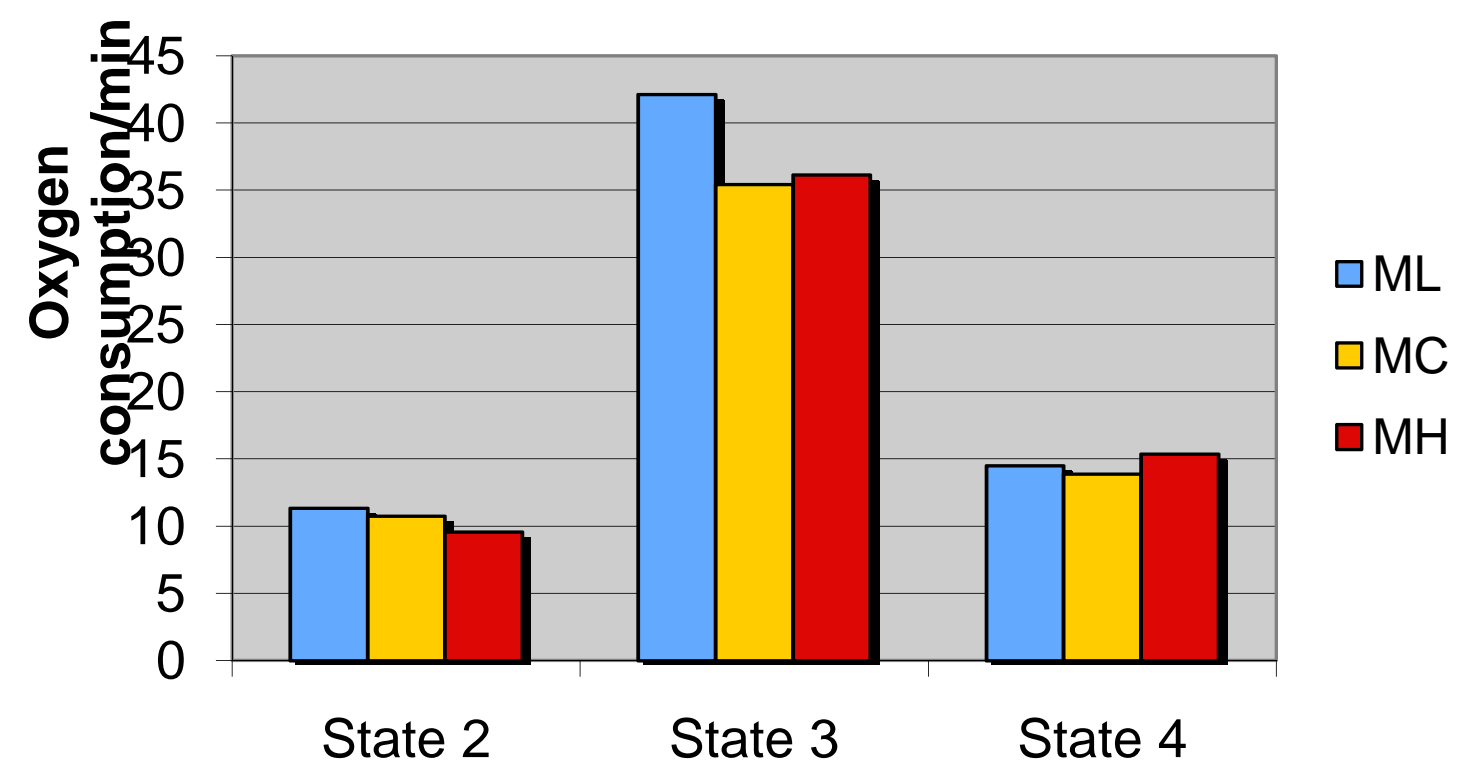

Figure 11. Mean rates of respiration for states 2, 3, and 4 for the low heat loss (ML), control (MC), and high heat loss (MH) lines of mice across all generations and replicates. 
There was an effect of selection for hepatic mitochondrial protein concentration $(\mathrm{P}=0.02)$ with $\mathrm{ML}$ mice having approximately $9 \%$ greater concentration than $\mathrm{MH}$ mice. There was no asymmetry effect $(\mathrm{P}=0.26)$, hence the $\mathrm{MC}$ mice were intermediate to the selected lines. Although McDonald et al. (2009) found differences in liver weights between the selected lines, they found no differences in hepatic mitochondrial protein. Bottje et al. (2002) isolated mitochondria from livers, among other tissues, of broilers from lines selected for high and low feed efficiency. They found no differences in mitochondrial protein concentration from any tissue between the lines. Ojano-Dirain et al. (2004) studied the same lines of broilers as Bottje et al. (2002). They extracted mitochondria from the duodenum of high and low feed efficient broilers and found no differences in mitochondrial protein concentration. Although the present study does not agree with the findings of others, a significant difference in hepatic mitochondrial protein was found between the heat loss selection lines.

Line means across all replicates and generations for all three states of respiration are presented in Table 4 and shown graphically in Figure 11. After succinate addition to the reaction chamber, state 2 respiration was initiated. The effect of selection was significant $(\mathrm{P}=0.045)$, the $\mathrm{ML}$ mice respired approximately $17 \%$ greater than the $\mathrm{MH}$ mice. No asymmetry effect was found $(\mathrm{P}=0.59)$ and the $\mathrm{MC}$ mice were intermediate to the selected lines. Following state 2 respiration, ADP was added to the reaction chamber to initiate state 3 respiration. The ML mice respired at a $15 \%$ greater rate than the $\mathrm{MH}$ mice although this only approached $(\mathrm{P}=0.066)$ significance. No asymmetry effect was found $(\mathrm{P}=0.14)$ so that the MC line was intermediate to the selected lines. After all of the ADP in the reaction chamber was consumed, the reaction entered state 4 respiration. 
There was no effect of selection $(\mathrm{P}=0.29)$, so there was no difference in state 4 respiration between the selection lines. Additionally, no asymmetry effect $(\mathrm{P}=0.14)$ was found although the MC mice had the lowest numerical state 4 respiration.

Bottje et al. (2002) reported the respiration rates of isolated mitochondria from high and low feed efficient lines of broilers after adding two different state 2 substrates. When succinate was used as the substrate, no significant differences between the lines were found for any states of respiration. Using the same lines as Bottje et al., OjanoDirian et al. (2004) reported the respiration rates of mitochondria isolated from the duodenum of birds. The high feed efficiency group exhibited $25 \%$ and $19 \%$ greater rates of respiration in states 2 and 3, respectively. Additionally, the high feed efficiency birds showed a $32 \%$ slower rate of respiration throughout state 4 .

Kolath et al. (2006) examined the role of mitochondrial efficiency in Angus steers placed in groups of low and high RFI. After isolating mitochondria from muscle they found the low RFI (more efficient) steers displayed 56\% greater state 2 and $50 \%$ greater state 3 respiration than the less efficient high RFI steers. There were no differences in state 4 respiration between the groups of animals. In the Nebraska heat loss selection lines McDonald et al. (2009) reported that mitochondria from the MH line respired at a greater rate $(\mathrm{P}<0.0001)$ than the ML line by approximately $17 \%$ throughout state 2 . They reported selection effects to approach significance during state $3(\mathrm{P}=0.06)$ as $\mathrm{MH}$ mitochondria respired at a $8 \%$ greater rate than ML. Additionally, MH mitochondria had a greater $(\mathrm{P}=0.02)$ state 3 respiration than ML mitochondria, approximately $19 \%$ faster. Asymmetry of selection was rejected for all states of respiration so the control line was not statistically different than the average of the selected lines. The results of McDonald 
et al. (2009) do not agree with others and the present study where more efficient lines generally respire at greater rates throughout state 2 and 3.

Mitochondrial efficiency is interpreted through measures of ATP production (ADP:O) and of degree of coupling within the electron transport chain (RCR). ADP:Os are calculated as the amount of ADP added (in $\mu$ moles) to initiate state 3 divided by the amount of oxygen (in $\mu$ moles) consumed throughout state 3 respiration. A larger ADP:O value indicates more efficient ATP synthesis. RCRs are calculated as the rate of state 3 respiration divided by the rate of state 4 respiration. Again, a greater RCR value indicates a higher degree of coupling and more efficient electron transport processes. Line means across all generations and replicates are presented in Table 5.

There was no line effect $(\mathrm{P}=0.998)$ for ADP:O. With this, there was no selection effect $(\mathrm{P}=0.98)$ or asymmetry effect $(\mathrm{P}=0.96)$. It can therefore be concluded that selection for heat loss had no effect on how efficiently ATP is synthesized within hepatic mitochondria of mice. Bottje et al. (2002) reported no line differences for ADP:O between the high and low feed efficient lines of broilers for mitochondria isolated from any tissue or while using either substrate (succinate or glutamate-malate). Agreeing with Bottje et al. (2002), Kolath et al. (2006) found no differences in ADP:O between high and low RFI steers when either substrate was used (succinate and glutamate). 


\begin{tabular}{|c|c|c|}
\hline${ }^{\mathrm{a}}$ Line & ADP:O & RCR \\
\hline ML & $1.43 \pm 0.05$ & $3.04 \pm 0.14$ \\
\hline $\mathrm{MC}$ & $1.43 \pm 0.06$ & $2.62 \pm 0.15$ \\
\hline $\mathrm{MH}$ & $1.43 \pm 0.06$ & $2.43 \pm 0.15$ \\
\hline
\end{tabular}

Table 5. Means \pm SE for RCR and ADP:O for the ML, MC, and MH lines across all replicates and generations.

${ }^{a}$ Line: $\mathrm{ML}=$ low heat loss, $\mathrm{MC}=$ unselected control, $\mathrm{MH}=$ high heat loss.

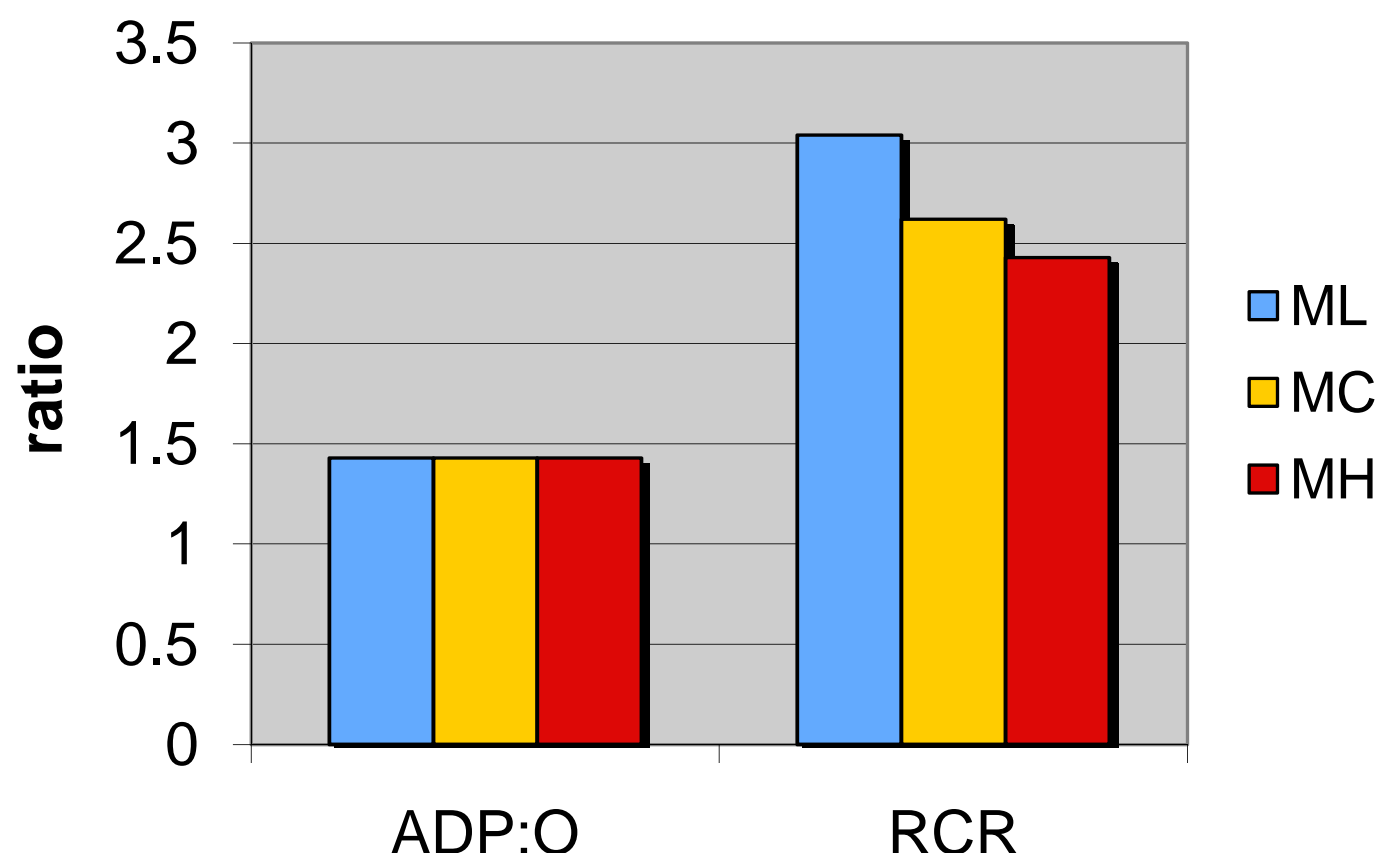

Figure 12. Means for ADP:O and RCR for the low heat loss (ML), control (MC), and high heat loss (MH) lines of mice across all generations and replicates. 
Examining hepatic mitochondria from the Nebraska heat loss lines, McDonald et al. (2009) found the ML mitochondria to have a greater ( $<0.01)$ ADP:O, approximately $20 \%$ greater than $\mathrm{MH}$. Additionally, the $\mathrm{MC}$ line was intermediate $(\mathrm{P}=0.20)$ and asymmetry was rejected. The results from McDonald et al. do not agree with others and the present study where no line differences were found for efficiency of ATP synthesis. Line means across all replicates and generations for ADP:O and RCR are shown graphically in Figure 12.

The line effect for $\mathrm{RCR}$ approached significance $(\mathrm{P}=0.052)$. There was a significant effect of selection $(\mathrm{P}=0.024)$ and $\mathrm{ML}$ mice showed a $22 \%$ greater RCR value. Additionally, asymmetry was rejected $(\mathrm{P}=0.48)$ so that the $\mathrm{MC}$ line was intermediate to the selected lines. These findings suggest that divergent selection for heat loss had an effect on how efficiently hepatic mitochondria carry out electron transport. The low heat loss, more efficient line of mice had a greater degree electron transport chain coupling.

Bottje et al. (2002) reported no differences between the high and low feed efficient lines of broilers for RCR when succinate was used as a substrate. However, when glutamate-malate was used as a substrate, breast and leg muscle mitochondria from the high feed efficient broilers exhibited greater $(\mathrm{P}<0.01)$ RCR values. Glutamatemalate donates electrons to Complex I in the electron transport chain where as succinate donates electrons to Complex II. The fact that Bottje et al. (2002) reported line differences in RCR when glutamate-malate was used but not when succinate was used as a substrate suggest uncoupling occurs earlier in the electron transport chain in broiler mitochondria. Kolath et al. (2006) found that low RFI steers had larger $(\mathrm{P}<0.05) \mathrm{RCR}$ 
values than the high RFI steers when both glutamate and succinate were used as a substrate. With this, they concluded that low RFI steers have a greater degree of electron transport chain coupling. In the mitochondrial efficiency study using the Nebraska heat loss lines, McDonald et al. (2009) reported the effect of selection approached significance $(\mathrm{P}=0.09)$ as the ML mice had $11 \%$ greater RCR values than the MH mice. Interestingly, McDonald et al. (2009) found the unselected MC line had the lowest numerical RCR values as asymmetry approached significance $(\mathrm{P}=0.08)$. The results of the present study agree, in part, with others as the more efficient ML line had a greater degree of electron transport chain coupling.

Assigning the fraction of line differences in Feed per BW that is explained by differences in $R C R$

The objective of the present study was to determine the extent, if any, mitochondrial efficiency has on the maintenance requirements of Nebraska heat loss selection lines. As previously mentioned, the only mitochondrial efficiency measurement that showed a significant selection effect was the respiratory control ratio. The regression coefficient of feed intake per BW was only estimated on RCR. The model to determine the percent of variation in feed intake per BW that can be explained by variation in RCR included the effects of Generation, Line, and Line*Replicate. After analyzing the results it was determined the regression coefficient was quite small, less than -0.0023 . The steps to determine the percent of variation in feed intake per BW that can be explained by variation in RCR are shown below. 


$$
\mathrm{b}_{\mathrm{FeedperBW} \cdot \mathrm{RCR}}=-0.00236
$$

\begin{tabular}{|c|c|c|c|}
\hline Trait & MH & ML & MH - ML \\
\hline \hline Feed per BW & 2.2158 & 1.5687 & 0.6471 \\
\hline RCR & 2.4342 & 3.0367 & -0.6025 \\
\hline
\end{tabular}

$(-0.6025) *(-0.00236)=0.001422$

0.001422

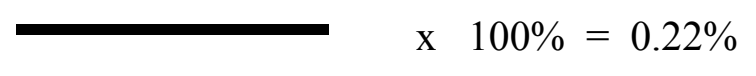

0.6471

The variation in feed intake per BW explained by variation in RCR is extremely small. Although there was a large effect of selection for RCR between the high and low heat loss lines, the small value suggests that RCR, how efficiently electron transport is carried out, does not account for differences in maintenance energy requirements, despite a relatively high repeatability for RCR at 0.78 .

In the similar study examining mitochondrial efficiency in the Nebraska heat loss selection lines, McDonald et al. (2009) reported the regression coefficients of feed intake per BW on the mitochondrial measurements. The present study's results were similar, with little or no relationship between feed intake per BW and mitochondrial traits. In fact, McDonald et al. (2009) reported the amount of variation in feed efficiency explained by variation in ADP:O was only $1.1 \%$. 


\section{Partial Correlation Coefficients}

Partial correlation coefficients of the traits reported earlier were calculated on a within generation-line-replicate basis and are displayed in Table 6. Significant negative relationships were found between feed intake per BW and percent fat. This suggests that animals that consume less feed are fatter as is generally found in the ML mice. A significant negative relationship was found between BW and feed intake per BW. This is because the MH line consumes the most feed, weighs the same as the ML line but weighs less than the MC line. A significant positive relationship exists between BW and percent fat as heavier animals are generally fatter.

There were significant positive relationships between the states of respiration, as one state of respiration became more negative (greater negative slope) the others were also more negative. There was a significant positive relationship between state 3 respiration and ADP:O so as mitochondria respired faster during state 3 they more efficiently synthesized ATP. Mitochondrial protein concentration was positively correlated with RCR; as a mitochondrial sample became more concentrated, the efficiency of electron transport increased. The slope of state 4 respiration was positively correlated with and RCR, as the slope of state 4 becomes less negative the RCR value becomes greater. 


\begin{tabular}{|c|c|c|c|c|c|c|c|c|c|c|}
\hline \multicolumn{7}{|c|}{ Partial Correlation Coefficients Between Traits (within generation-line-replicate) } \\
\hline Trait $^{\text {a }}$ & BW & Feed & LW & FAT & MitoP & mS2 & mS3 & mS4 & RCR & ADPO \\
& & & & & & & & & & \\
\hline BW & 1.00 & -0.46 & -0.05 & 0.35 & -0.03 & -0.07 & -0.05 & -0.06 & -0.03 & -0.03 \\
P val & & $<.0001$ & 0.4937 & $<.0001$ & 0.69 & 0.37 & 0.50 & 0.44 & 0.69 & 0.71 \\
\hline Feed & & 1.00 & 0.09 & -0.39 & -0.02 & 0.08 & 0.07 & 0.11 & 0.05 & -.04 \\
P val & & & 0.26 & $<.0001$ & 0.80 & 0.30 & 0.36 & 0.16 & 0.52 & 0.58 \\
\hline LW & & & 1.00 & -0.06 & -0.004 & 0.07 & -0.002 & 0.05 & 0.15 & -.03 \\
P val & & & & 0.47 & 0.96 & 0.41 & 0.98 & 0.49 & 0.06 & 0.70 \\
\hline FAT & & & & 1.00 & -0.06 & -0.12 & -0.11 & -0.04 & 0.12 & 0.05 \\
P val & & & & & 0.46 & 0.12 & 0.16 & 0.58 & 0.13 & 0.51 \\
\hline MitoP & & & & & 1.00 & -0.14 & -0.07 & 0.05 & 0.21 & -0.14 \\
P val & & & & & & 0.08 & 0.38 & 0.55 & 0.01 & 0.07 \\
\hline mS2 & & & & & 1.00 & 0.70 & 0.62 & 0.02 & 0.01 \\
P val & & & & & & & $<.0001$ & $<.0001$ & 0.88 & 0.87 \\
\hline mS3 & & & & & & 1.00 & 0.83 & -0.07 & 0.21 \\
P val & & & & & & & & $<.0001$ & 0.35 & 0.01 \\
\hline mS4 & & & & & & & & 1.00 & 0.44 & 0.25 \\
P val & & & & & & & & & $<.0001$ & 0.002 \\
\hline RCR & & & & & & & & 1.00 & 0.11 \\
P val & & & & & & & & & & 0.16 \\
\hline ADPO & & & & & & & & & & 1.00 \\
P val & & & & & & & & & & \\
\hline
\end{tabular}

Table 6. Partial correlation coefficients of traits measured within generation-line-replicate and the interaction of line and replicate; highlighted areas indicate correlations between two traits that met significance level of $\alpha=0.05$

${ }^{\mathrm{a}} \mathrm{BW}=$ average body weight $(\mathrm{g})$ over 2-wk feed intake trial; Feed $=$ feed intake per BW $(\mathrm{g} / \mathrm{g})$ over feed intake trial; $\mathrm{LW}=$ liver weight per BW $(\mathrm{g} / \mathrm{g})$; FAT = percent fat; MitoP = mitochondrial protein concentration $(\mathrm{mg} / \mathrm{mL}) ; \mathrm{mS} 2=$ average State 2 respiration $(\mu \mathrm{mol}$ $\mathrm{O}_{2} / \mathrm{min}$ ); $\mathrm{mS} 3$ = average State 3 respiration; $\mathrm{mS} 4=$ average State 4 respiration; $\mathrm{RCR}=$ respiratory control ratio; and $\mathrm{ADPO}=\mathrm{ADP}: \mathrm{O}$. 
Of the studies examining mitochondrial efficiency and its relationship to feed efficiency, few have reported the correlations between the two. Bottje et al. (2002) reported that RCR values were correlated with feed efficiency when breast and leg mitochondria data were analyzed $\left(\mathrm{r}^{2}=0.72, \mathrm{P}<0.0001\right.$ and $\mathrm{r}^{2}=0.37, \mathrm{P}<0.01$, respectively). However, the authors found no correlations of RCR with feed efficiency when hepatic mitochondria were analyzed. Additionally, McDonald et al. (2009) found no significant correlations between feed per BW and RCR or ADP:O. Results from the present study agree with Bottje et al. (2002) and McDonald et al. (2009), no relationship was observed between hepatic mitochondrial RCR measurements and feed efficiency at maintenance.

\section{Suggestions for Further Research}

\section{Further Investigating Mitochondrial Efficiency}

Although we have not found feed intake per BW to be related to mitochondrial efficiency, significant differences between the high and low heat loss lines have been found in mitochondrial respiration. The ML line respires statistically and numerically greater throughout states 2 and 3. Additionally, the ML line shows a larger degree of electron transport chain coupling which was determined by a larger respiratory control ratio. The question that remains is: how can we explain these differences? Perhaps these differences can be explained by proton leak and characteristics of the electron transport chain, both of which can be measured with the proper equipment. 
To some extent, proton leak can be measured by the concentration of uncoupling proteins (UCP) present in tissues. The UCP homologues act in different ways to uncouple electron transport with oxidative phosphorylation. Some researchers have hypothesized the biological reasoning for UCP homologues. McDaneld et al. (2002) utilized the Nebraska heat loss selection lines to investigate the presence of UCP1. They found that the ML line had approximately $93 \%$ more UCP1 than the MH line. Since UCP1 has been noted to cause inefficiency in mitochondrial activity, the results of McDaneld et al. (2002) were unexpected. There are several other UCP homologues that have been identified in mammals. Ricquier and Bouillaud (2000) used Western blot and immunoprecipitation to identify and quantify UCP1, 2, and 3.

Slippage of the electron transport chain increases the amount of reactive oxygen species and leads to inefficiencies. One reactive oxygen species that has been identified and measured in livestock species is hydrogen peroxide $\left(\mathrm{H}_{2} \mathrm{O}_{2}\right)$. The procedure to isolate mitochondria and measure $\mathrm{H}_{2} \mathrm{O}_{2}$ was outlined by Bottje et al. (2002). Bottje et al. (2002) and Ojano-Dirain et al. (2004) used the same lines of broilers to study $\mathrm{H}_{2} \mathrm{O}_{2}$ production. They both found that low feed efficient birds produced more $\mathrm{H}_{2} \mathrm{O}_{2}$ than the high feed efficient birds. Similarly, Kolath et al. (2006) found that steers with the low RFI phenotype produced less $\mathrm{H}_{2} \mathrm{O}_{2}$ than high RFI steers.

The electron transport chain has two sites to accept electrons. Complex I accepts electrons from $\mathrm{NADH}$ and Complex II accepts electrons from $\mathrm{FADH}_{2}$. After introduction of rotenone (which blocks activity of Complex I) to the reaction chamber, electron transport chain activity can be studied from Complex II on. This was the procedure used in the present study and, as previously stated, no relationship between feed intake per BW 
and RCR was found. Without blocking Complex I activity, a glutamate substrate can be added to the reaction chamber and the whole electron transport chain can be studied. This procedure was carried out by Bottje et al. (2002), Ojano-Dirain et al. (2004), and Kolath et al. (2006) with various tissues. They found significant differences in mitochondrial efficiency between high and low feed efficient animals.

Sharifabadi et al. (2012) identified lambs displaying high and low feed efficiency and then examined the activity of Complexes I, II, III, IV, and ATP Synthase. They found that all 5 complexes exhibited greater activity in sheep displaying the low RFI phenotype. If these protocols of the aforementioned studies could be replicated at the University of Nebraska-Lincoln, perhaps a better understanding of mitochondrial efficiency can be attained. 
Summary and Conclusions 
Using direct calorimetry, mice have been divergently selected for heat loss throughout a total of 25 generations at the University of Nebraska-Lincoln. An unselected control line was also created and 3 replications of each line (ML, MC, and MH) have been maintained throughout all generations. Selection for heat loss has created large differences in maintenance requirements, with the MH line consuming the most feed. Although differences in feed intake throughout maintenance exists, no difference in BW has ever been reported between the selected lines. However, the unselected control line weighs more than selected lines. This suggests that 2 separate mechanisms have resulted from heat loss selection that affects the BW of the selected mice. Others have found that divergent selection for heat loss has also resulted in line differences in fat percentage, liver weight per BW, and locomotor activity. The present study did not find statistical line differences in fat percentage and liver weight per BW. However, the MH line was found to consume $34 \%$ more feed than the ML line.

It was found that mitochondria from the ML mice respired at a greater rate throughout state 2 respiration. No line differences were found for ADP:O, a measurement of the efficiency of ATP synthesis. However, ML mice had, on average, 22\% larger RCR values than the MH mice. This suggests that ML mice exhibit a greater degree of electron transport chain coupling. Although there were significant line differences for mitochondrial efficiency, regression analysis revealed that it explained essentially no variation in feed intake per BW. Additionally, the correlations with feed intake per BW and these mitochondrial traits were insignificant. Perhaps this is can be explained by a large within line variation in mitochondrial traits but a small within line variation for 
maintenance requirements. However, it is evident that divergent selection for heat loss has resulted in differences in mitochondrial efficiency.

Future research should center on what else causes these differences in mitochondrial efficiency. The experimental design to determine this could include measuring mitochondrial efficiency in other tissues including skeletal muscle, brain, and heart while using different reaction substrates. Additionally one could explore uncoupling protein homologue concentrations, the generation of reactive oxygen species, and the individual complex activities within the electron transport chain to find differences among these heat loss selection lines. This study demonstrates the complex cellular and sub-cellular relationships that separate efficient animals from inefficient ones. 


\section{Literature Cited}


BIF. 1986. Guidelines for Uniform Beef Improvement Programs. Beef Improvement Federation, USDA Ext. Service, Program Aid 1020.

Bishop, M. D., M. E. Davis, W. R. Harvey, G. R. Wilson, and B. D. VanStarvern. 1991a. Divergent selection for postweaning feed conversion in angus beef cattle: I. mean comparisons. J. Anim. Sci. 69:4348-4359.

Bishop, M. D., M. E. Davis, W. R. Harvey, G. R. Wilson, and B. D. VanStarvern. 1991b. Divergent selection for postweaning feed conversion in angus beef cattle: II. Genetic and phenotypic correlations and realized heritability estimate. J. Anim. Sci. 69:4360-4367.

Bottje, W. G. and G. E. Carstens. 2009. Association of mitochondrial function and feed efficiency in poultry and livestock species. J. Anim. Sci. 87:E48-E63.

Bottje, W. G., A. X. Tang, M. Iqbal, D. Cawthon, R. Okimoto, T. Wing, and M. Cooper. 2002. Association of mitochondrial function with feed efficiency within a single genetic line of male broilers. Poul. Sci. 81:546-555.

Boveris, A., B. Chance. 1973. The mitochondrial generation of hydrogenperoxide. Biochem J. 134:707-711.

Brand, M. D., L. Chien, E. K. Ainscow, D. Rolfe, and R. K. Porter. 1994. The causes and functions of mitochondrial proton leak. Biochem. Biophys. Acta. 1187:132-139.

Brown, D. R., S. K. DeNise, and R. R. McDaniel. 1986. Hepatic mitochondrial activity in two breeds of chicken. Poult. Sci. 65:613-615.

Brown, D. R., S. K. DeNise, and R. R. McDaniel. 1987. Phenotypic variation in respiratory metabolism and complementation of murine hepatic mitochondria. Theor. Appl. Genet. 75:189-193.

Brown, G. C. 1992. The leaks and slips of bioenergetic membranes. FASEB J. 6:29612965.

Canolty, N. L. and L. J. Koong. 1976. Utilization of energy for maintenance and for fat and lean gains by mice selected for rapid postweaning growth rate. J. Nutr. 106:1202-1208.

Dunnington, E. A. and P. B. Siegel. 1996. Long-term divergent selection for eight-week body weight in Plymouth rock chickens. J. Poultry Sci. 75:1168-1179.

Eggert, D. L. and M. K. Nielsen. 2006. Comparison of feed energy costs of maintenance, lean deposition, and fat deposition in three lines of mice selected for heat loss. J. Anim. Sci. 84:276-282. 
Ferrel, C. L., and T. G. Jenkins. 1985. Cow type and the nutritional environment: nutritional aspects. J. Anim. Sci. 61:725-741.

Hansatech Instruments. 2000. Oxygen measurements in the liquid phase- systems manual. Hansatech instruments limited. Norfolk, England.

Hotovy, S. K., K. A. Johnson, D. E. Johnson, G. E. Carstens, R. M. Bourdon, and G. E. Seidel, Jr. 1991. Variation among twin beef cattle in maintenance energy requirements. J. Anim. Sci. 69:940-946.

Jensen, J., I. L. Mao, B. B. Andersen, P. Madsen. 1992. Phenotypic and genetic relationships between residual energy intake and growth, feed intake, and carcass traits of young bulls. J. Anim. Sci. 70:386-395.

Ježek, P. M., M. Žáčková, E. Růžička, E. Š Kkobisová, M. Jabůrek. 2004. Mitochondrial uncoupling proteins- facts and fantasies. Physiol. Res. 53:S199-S211.

Kgwatalala, P. M. and M. K. Nielsen. 2004. Performance of mouse lines divergently selected for heat loss when exposed to different environmental temperatures. II. intake, growth, fatness, and body organs. J. Anim. Sci. 82:2884-2891.

Kolath, W. H., M. S. Kerley, J. W. Golden, and D. H. Keisler. 2006. The relationship between mitochondrial function and residual feed intake in angus steers. J. Anim. Sci. 84:861-865.

Lehinger, A. L.1970. Biochemistry. Worth Publishers, Inc. 395-408.

Luiting, P. and E. M. Urff. 1991. Residual feed consumption in laying hens. 1. quantification of phenotypic variation and repeatabilities. Poult. Sci. 70:16551662.

McDaneld, T. G., M. K. Nielsen, and J. L. Miner. 2002. Uncoupling protein and energy expenditure in mice divergently selected for heat loss. J. Anim. Sci. 80:602-608.

McDonald, J. M. and M. K. Nielsen. 2007. Renewed selection for heat loss in mice: direct responses and correlated responses in feed intake, body weight, and litter size and conception rate. J. Anim. Sci. 85:658-666.

McDonald, J. M., J. J. Ramsey, J. L. Miner, and M. K. Nielsen. 2009. Differences in mitochondrial efficiency between lines of mice divergently selected for heat loss. J. Anim. Sci. 87:3105-3113.

Moody, D. E., D. Pomp, and M. K. Nielsen. 1997. Variability in metabolic rate, feed intake and fatness among selection and inbred lines of mice. Genet. Res. 70:225235 . 
Mousel, M. R., W. W. Stroup, and M. K. Nielsen. 2001. Locomotor activity, core body temperature, and circadian rhythms in mice selected for high or low heat loss. J. Anim. Sci. 79:861-868.

Mukherjee, T. K., R. W. C. Stevens, and M. P. Hoogendoorn. 1970. Oxygen uptake of mitochondrial isolates from two breeds of chickens and their F1 crosses. Poult. Sci. 49:1130-1131.

NRC. 1996. Nutrient Requirements of Beef Cattle. National Academy Press. Washington, D.C.

Nielsen, M. K., L. D. Jones, B. A. Freking, and J. A. DeShazer. 1997a. Divergent selection for heat loss in mice: I. selection applied and direct response through fifteen generations. J. Anim. Sci. 75:1461-1468.

Nielsen, M. K., L. D. Jones, B. A. Freking, S. M. Nelson, T. L. Vordorstrasse, and B. A. Hussey. 1997b. Divergent selection for heat loss in mice: II. correlated responses in feed intake, body mass, body composition, and number born through fifteen generations. J. Anim. Sci. 75:1469-1476.

Ojano-Dirain, C. P., M. Iqbal, D. Cawthon, S. Swonger, T. Wing, M. Cooper, and W. Bottje. 2004. Determination of mitochondrial function and site-specific defects in transport in duodenal mitochondria in broilers with low and high feed efficiency. Poult. Sci. 83:1394-1403.

Petersen, C. L. 1998. Mitochondrial investigations as they relate to whole plant respiration and stress/heat tolerance. M.S. Thesis. University of NebraskaLincoln.

Richardson, E. C., R. M. Herd, J. A. Archer, R. T. Woodgate, and P. F. Arthur. 1998. Steers bred for improved net feed efficiency eat less for the same feedlot performance. An. Prod. Aust. 22:213-216.

Ricquier, D. and F. Bouillaud. 2000. The uncoupling protein homologues: UCP1, UCP2, UCP3, StUCP, and AtUCP. Biochem. J. 345:161-179.

Rios, J. G., M. K. Nielsen, G. E. Dickerson and J. A. DeShazer. 1986. Selection for postweaning gain in rats: I. correlated response in feed utilization and body composition. J. Anim. Sci. 63:34-45.

Rolfe, D. and G. Brown. 1997. Cellular energy utilization and molecular origin of standard metabolic rate in mammals. Physiol. Rev. 77:731-758. 
Sharifabadi, H. R., M. J. Zamiri, E. Rowghani, and W. G. Bottje. 2012. Relationship between the activity of mitochondrial respiratory chain complexes and feed efficiency in fat-tailed ghezel lambs. J. Anim. Sci. 90:1807-1815.

Shuey, S. A., C. P. Birkelo, and D. M. Marshall. 1993. The relationship of the maintenance energy requirement to heifer production efficiency. J. Anim. Sci. $71: 2253-2259$.

Smith, R. M., N. K. Gabler, J. M. Young, W. Cai, N. J. Boddicker, M. J. Anderson, E. Huff-Lonergan, J. C. M. Dekkers, and S. M. Lonergan. 2011. Effects of selection for decreased residual feed intake on composition and quality of fresh pork. J. Anim. Sci. 89:192-200. 
